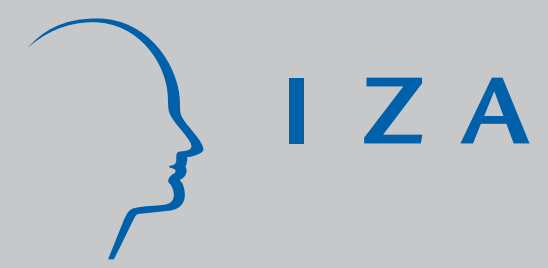

IZA DP No. 8548

Estimation of Dynamic Discrete Choice Models by Maximum Likelihood and the Simulated Method of Moments

Philipp Eisenhauer

James J. Heckman

Stefano Mosso

October 2014 


\title{
Estimation of Dynamic Discrete Choice Models by Maximum Likelihood and the Simulated Method of Moments
}

\author{
Philipp Eisenhauer \\ University of Chicago \\ James J. Heckman \\ University of Chicago, CEHD, \\ American Bar Foundation and IZA \\ Stefano Mosso \\ University of Chicago
}

Discussion Paper No. 8548

October 2014

\author{
IZA \\ P.O. Box 7240 \\ 53072 Bonn \\ Germany \\ Phone: +49-228-3894-0 \\ Fax: +49-228-3894-180 \\ E-mail: iza@iza.org
}

\begin{abstract}
Any opinions expressed here are those of the author(s) and not those of IZA. Research published in this series may include views on policy, but the institute itself takes no institutional policy positions. The IZA research network is committed to the IZA Guiding Principles of Research Integrity.

The Institute for the Study of Labor (IZA) in Bonn is a local and virtual international research center and a place of communication between science, politics and business. IZA is an independent nonprofit organization supported by Deutsche Post Foundation. The center is associated with the University of Bonn and offers a stimulating research environment through its international network, workshops and conferences, data service, project support, research visits and doctoral program. IZA engages in (i) original and internationally competitive research in all fields of labor economics, (ii) development of policy concepts, and (iii) dissemination of research results and concepts to the interested public.
\end{abstract}

IZA Discussion Papers often represent preliminary work and are circulated to encourage discussion. Citation of such a paper should account for its provisional character. A revised version may be available directly from the author. 


\begin{abstract}

\section{Estimation of Dynamic Discrete Choice Models by Maximum Likelihood and the Simulated Method of Moments ${ }^{*}$}

We compare the performance of maximum likelihood (ML) and simulated method of moments (SMM) estimation for dynamic discrete choice models. We construct and estimate a simplified dynamic structural model of education that captures some basic features of educational choices in the United States in the 1980s and early 1990s. We use estimates from our model to simulate a synthetic dataset and assess the ability of ML and SMM to recover the model parameters on this sample. We investigate the performance of alternative tuning parameters for SMM.
\end{abstract}

JEL Classification: C13, C15, C35, 121

Keywords: returns to education, dynamic discrete choice, simulation-based estimation

Corresponding author:

Philipp Eisenhauer

Department of Economics

The University of Chicago

1126 East 59th Street

Chicago, IL 60637

USA

E-mail: info@policy-lab.org

\footnotetext{
* We thank George Yates for numerous valuable comments, for excellent computational assistance in developing the maximum likelihood estimator used in this paper, and for assisting in the study of accuracy bounds for the computational algorithm. We thank Edward Sung and Jake Torcasso for their outstanding research assistance. We have benefited greatly from comments received from Chris Flinn, Kenneth Judd, Michael Keane, Bernard Salanié, Petra Todd, and Stefan Wild. We thank the editor and anonymous referees for their valuable comments. This research was supported in part by the American Bar Foundation, the Pritzker Children's Initiative, the Buffett Early Childhood Fund, NICHD 5R37HD065072, 5R01HD054702, the Human Capital and Economic Opportunity Global Working Group - an initiative of the Becker Friedman Institute for Research in Economics - funded by the Institute for New Economic Thinking (INET), and an anonymous funder. Philipp Eisenhauer thanks Prof. Wolfgang Franz and the Centre for European Economic Research (ZEW Mannheim) for their support. The views expressed in this paper are those of the authors and not necessarily those of the funders or commentators mentioned here. The website for this paper is https://heckman.uchicago.edu/ MLVSSMM.
} 


\section{Introduction}

Economic science uses economic theory to guide the interpretation of economic data and to shape policy. Kenneth Wolpin is a model economic scientist who integrates theory and data in a rigorous fashion. He summarizes his philosophy toward empirical research in Wolpin (2013). He is a major contributor to structural econometrics with particular emphasis on the study of dynamic discrete choice models. His contributions are both methodological and empirical. His methodological research focuses on promoting methods to increase the reliability of algorithms for structural estimation (Eckstein and Wolpin, 1989; Keane et al. 2011) and developing techniques to simplify their empirical implementation. His research on interpolation methods to solve dynamic discrete choice models with a large state space (Keane and Wolpin, 1994) is a prominent example. In his empirical contributions, he extensively applies theory-motivated methods to investigate many important issues such as educational attainment (Eckstein and Wolpin, 1999: Keane and Wolpin, 1997), the role of credit constraints in educational attainment (Keane and Wolpin, 2001), and labor market dynamics (Lee and Wolpin, 2006, 2010).

This paper contributes to the literature on estimating dynamic discrete choice models. It investigates the empirical performance of widely used versions of simulated method of moments (SMM), a computationally tractable method for estimating complex structural models. SMM estimates parameters by fitting a vector of empirical moments to their theoretical counterparts simulated from a structural model (McFadden, 1989). We compare its performance against standard maximum likelihood (ML) estimation 1

${ }^{1}$ Alternative estimation methods have been proposed to overcome the rigidities and complexities of ML estimation. Most require the analyst to characterize the likelihood function but simplify its computation. One of the most popular methods, simulated ML (SML), substitutes the exact likelihood function with a simulated one. An example is the Hajivassiliou-Geweke-Keane (HGK-SML) estimator (Geweke, 1989; Hajivassiliou and McFadden, 1998; Keane, 1994) used for multinomial probit estimation. Approximations of the dynamic programming problem have often been combined with SML in models with a large state space (Keane and Wolpin, 1994). Another popular method is the conditional 
We estimate a deliberately simplified dynamic discrete choice model of schooling based on a sample of white males from the National Longitudinal Survey of Youth (1979) using ML. Our model is more restrictive compared to standard dynamic discrete choice models (Keane and Wolpin, 1997, 2001) with respect to the number of choices and the timing of decisions and outcomes. We restrict agents to binary choices and our model is based on educational states. This allows us to evaluate the likelihood analytically, without the need for any simulation or interpolation (Keane, 1994), which provides a clean comparison of ML against simulation-based estimation methods such as SMM. Using the estimates of model parameters, we simulate a synthetic dataset. In a series of Monte Carlo studies we compare estimates based on our precisely calculated ML with those from widely used, computationally tractable versions of SMM. Because our synthetic sample is derived from real data, our analysis provides useful lessons on the performance of SMM for the estimation of structural models. ${ }^{2}$

SMM has been used to estimate models of job search (Flinn and Mabli, 2008), educational and occupational choices (Adda et al., 2013, 2011), household choices (Flinn and Del Boca, 2012), stochastic volatility models (Andersen et al., 2002; Raknerud and Skare, 2012), and dynamic stochastic general equilibrium models (Ruge-Murcia, 2012). SMM can be used for any model, however complex or difficult to compute the likelihood, as long as it is possible to simulate it. Under conditions presented in the literature, the SMM estimator is consistent and asymptotically normal (Gouriéroux and Monfort, 1997). If the score vector for SMM happens to be correctly specified, then SMM is asymptotically efficient (Gallant and Tauchen, 1996; Gouriéroux et al., 1993) $!^{3}$

choice probabilities (CCP) algorithm first proposed by Hotz and Miller (1993) and recently extended to allow for unobserved heterogeneity (Arcidiacono and Miller, 2011). Using CCP, a consistent estimator of the model parameters can be derived without the need of the full solution of the dynamic programming problem. The CCP method, however, restricts the flexibility of the estimable models by imposing assumptions which limit the dependence among successive choices. SMM is a more general alternative to ML estimation.

${ }^{2}$ As in Skrainka (2011), we use simulation experiments in realistic settings to investigate the finite sample behavior of widely-used estimators.

${ }^{3}$ See Nickl and Pötscher (2010) and Gach and Pötscher (2011) for recent additional results. 
Implementing any estimation strategy requires numerous choices. In the case of SMM, users have discretion in selecting: (1) the moments used in estimation, (2) the number of replications used to compute the simulated moments, (3) the moment weighting matrix, and (4) the algorithm used for optimization. It is unclear how such choices affect the performance of the SMM estimator and how they depend on the structure of the model estimated. We propose diagnostic tools to test their validity.

We suggest a Monte Carlo procedure that allows SMM users to gain confidence for their particular implementation of the algorithm. We present a new optimization algorithm for solving derivativefree nonlinear least-squares problems that is well-suited for conventional SMM implementations. A benchmarking exercise demonstrates significant speed improvements compared to the algorithms commonly used in the literature. Combining state of the art optimization methods with parallel computing allows analysts to perform our proposed Monte Carlo exercise even in computation-intensive models.

We present our schooling model in Section 2 . Section 3 presents baseline results. Section 4 outlines our Monte Carlo study and compares the performance of ML and SMM estimation. Section 5 concludes.

\section{Dynamic Model of Educational Choices}

This section presents a computationally tractable dynamic discrete choice model of education and establishes conditions when it is identified. We specify a model with a simple state space by assuming that agents move from one schooling state to the next. Agents are assumed to have two choices at each decision node. The value of each state is determined by its immediate rewards and costs, and by the expected future value of all feasible states made available by a choice. Agents have private information on their own type and form expectations about future states with respect to their current information set.

Our simple specification comes at the expense of a less realistic empirical analysis of the dynamics of schooling choices compared to those of Keane and Wolpin (1997, 2001) and Johnson (2013). We restrict agents to binary choices and our model is based on educational states. We make these assump- 
tions because they allow us to evaluate the likelihood without any simulation, which provides a clean comparison of ML estimation with simulation-based alternatives.

\subsection{Setup}

Given the current state $s \in \mathcal{S}=\left\{s_{1}, \ldots, s_{N}\right\}$, let $\mathcal{S}^{v}(s) \subseteq \mathcal{S}$ denote the set of visited states and $\mathcal{S}^{f}(s) \subseteq \mathcal{S}$ the set of feasible states that can be reached from $s$. We collect the choice set of the agent in state $s$ in $\Omega(s)=\left\{s^{\prime} \mid s^{\prime} \in \mathcal{S}^{f}(s)\right\}$. We consider binary choices only, so $\Omega(s)$ has at most two elements. Ex post, the agent receives per period rewards $R\left(s^{\prime}\right)=Y\left(s^{\prime}\right)-C\left(s^{\prime}, s\right)$ defined as the difference between per period earnings, $Y\left(s^{\prime}\right)$ and the costs $C\left(s^{\prime}, s\right)$ associated with moving from state $s$ to state $s^{\prime}$. The costs combine monetary expenses such as tuition and psychic costs (e.g. Cunha et al. (2005)). We can only identify the differences in the costs for two alternative states. We thus normalize the cost of one of the exits to zero. In the subsequent analysis it is useful to explicitly distinguish between the nonzero $\left(\hat{s}^{\prime}\right)$ and zero cost $\left(\tilde{s}^{\prime}\right)$ exits from $s$. We collect the subset of states with a costly exit in $S^{c}$. We assume earnings and costs are separable functions of observed covariates $X(s) \in \mathcal{X}$ for earnings and $Q\left(\hat{s}^{\prime}, s\right) \in \mathcal{Q}$ for costs. There is a stochastic component $\left(U_{Y}(s), U_{C}\left(\hat{s}^{\prime}, s\right)\right)$ to each of them. Earnings are expressed as:

$$
Y(s)=\mu_{s}(X(s))+U_{Y}(s)
$$

The costs of going from state $s$ to state $\hat{s}^{\prime}$ are defined by:

$$
C\left(\hat{s}^{\prime}, s\right)=K_{\hat{s}^{\prime}, s}\left(Q\left(\hat{s}^{\prime}, s\right)\right)+U_{C}\left(\hat{s}^{\prime}, s\right) .
$$

Some variables in $Q\left(\hat{s}^{\prime}, s\right)$ and $X\left(s^{\prime}\right)$ might be the same. Their distinct elements constitute the exclusion restrictions.

We impose a factor structure on the unobservables by postulating that a low dimensional vector of latent factors $\theta$ is the sole source of dependency among the unobservables of the model (Cunha et al. 
2005: Hansen et al. 2004):

$$
U_{Y}(s)=\theta^{\prime} \alpha_{s}+\epsilon(s) \quad U_{C}\left(\hat{s}^{\prime}, s\right)=\theta^{\prime} \varphi_{\hat{s}^{\prime}, s}+\eta\left(\hat{s}^{\prime}, s\right) .
$$

The individual-specific factors $\theta$ are known to agents but unknown to the econometrician, while the idiosyncratic shocks $\epsilon(s)$ and $\eta\left(\hat{s}^{\prime}, s\right)$ are unknown to the econometrician and only known by the agents at different stages of the decision process. The idiosyncratic shocks are independent but not identically distributed. We thus generalize the i.i.d. innovation assumption in Keane and Wolpin (1997). The impact of these traits on earnings and costs is given by the factor loadings $\left(\alpha_{s}, \varphi_{\hat{s}^{\prime}, s}\right)$. We allow for unobservable correlations in outcomes and choices across states through $\theta$ and the loadings vary by states.

Following Carneiro et al. (2003), Cunha et al. (2010), and Heckman et al. (2013), we assume access to a $J$ dimensional vector of individual measures $M$ (such as test scores or behavioral indicators) proxying individual factors $\theta$. We use the measures as noisy signals of the factors $\theta$ :

$$
M(j)=\mu_{j}(X(j))+\theta^{\prime} \gamma_{j}+v(j) \quad \text { for } j=1, \ldots, J
$$

We assume that $\epsilon(s), \eta\left(\hat{s}^{\prime}, s\right)$, and $v(j)$ are mutually independent for all $j, s, \hat{s}^{\prime}$. In measurement system (3), we interpret the unobserved factors as individual specific traits.

We assume that agents are risk neutral and maximize discounted lifetime rewards when making their educational choices. When an agent makes his educational choice to proceed from state $s$ to $s^{\prime}$, he knows the stochastic component of the transition $\eta\left(\hat{s}^{\prime}, s\right)$ but not of future earnings $\epsilon\left(s^{\prime}\right)$. The assumed timing of the arrival of information is as follows:

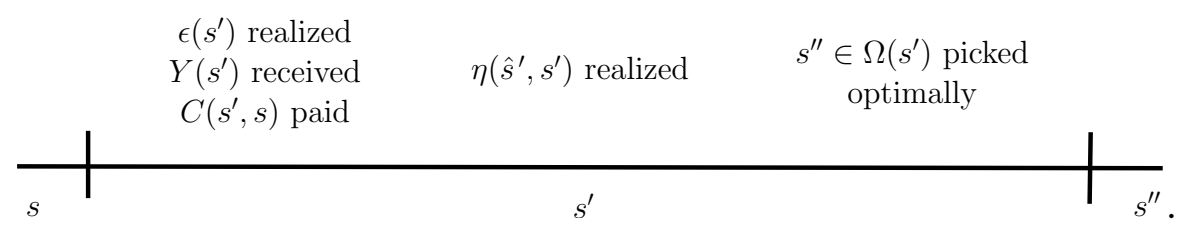

The agents know $X(s), Q\left(\hat{s}^{\prime}, s\right)$, and $\theta$ for all $s$. Under this timeline, we define $\mathcal{I}(s)$ as the information 
set of the agent in state $s$ by specifying all components known in the state:

$$
\left.\begin{array}{ll}
\text { for all } s \in \mathcal{S}^{v}(s) & \eta\left(\hat{s}^{\prime}, s\right) ; \epsilon(s) \\
\text { for } \hat{s}^{\prime} \in \mathcal{S}^{f}(s) & \eta\left(\hat{s}^{\prime}, s\right) \\
\text { and for all } s & X(s) ; Q\left(\hat{s}^{\prime}, s\right) ; \theta
\end{array}\right\} \in \mathcal{I}(s) \text {. }
$$

The agents in state $s$ know the costs associated with a transition to any feasible state $s^{\prime}$. We assume that the agent uses the distributions for the earnings shocks $\epsilon(s)$, denoted by $F_{E, s}(\epsilon(s))$, and for the transition costs shock $\eta\left(\hat{s}^{\prime}, s\right)$, denoted by $F_{H, \hat{s}^{\prime}, s}\left(\eta\left(\hat{s}^{\prime}, s\right)\right)$, to form expectations about future states. The distributions of the shocks can vary across states ${ }^{4}$

${ }^{4}$ We differ from Keane and Wolpin (1997) in our specification of the distribution of the unobserved components. In their specification, agents have different initial conditions for each state variable. The distribution of initial conditions is multinomial with five components. They assume that there are only four types (values) of initial conditions in the population. Serial dependence is induced through the persistence of the initial conditions as determinants of current state variables. In addition, at each age the agent receives five shocks associated with the rewards of each choice. The shocks are joint normally distributed, serially uncorrelated, and they are assumed to be i.i.d. over time.

In our model, we allow for state dependence in the distribution of the unobservables by letting earnings and cost shocks be drawn from normal distributions with different variances at each state and at each transition. Moreover, we allow unobserved portions of cost and return functions to be contemporaneously and serially correlated through their common dependence on the factors $\theta$. Our $\theta$ are normally distributed so we have a continuum of types. The Keane and Wolpin (1997) specification of persistent heterogeneity is a version of a factor model in which all factor loadings are implicitly determined (through Bellman iterations) by the parameters of the deterministic portions of cost and return functions and the distribution functions of unobserved variables and the sample distribution of observables. In our approach, the factor loadings are specified independently of the parameters of the deterministic portions of the cost and return functions and the sample distribution of observed variables. 
We define the agent's value function at state $s$, given the available information in $s$, recursively as:

$$
V(s)=Y(s)+\max _{s^{\prime} \in \Omega(s)}\left\{\frac{1}{1+r}\left(-C\left(s^{\prime}, s\right)+\mathbb{E}\left[V\left(s^{\prime}\right) \mid \mathcal{I}(s)\right]\right)\right\}
$$

For future reference we define the continuation value of state $s$ as the second term on the right hand side of (4):

$$
C V(s)=\max _{s^{\prime} \in \Omega(s)}\left\{\frac{1}{1+r}\left(-C\left(s^{\prime}, s\right)+\mathbb{E}\left[V\left(s^{\prime}\right) \mid \mathcal{I}(s)\right]\right)\right\}
$$

The agent's policy function determines the optimal transitions. An agent in s chooses his next feasible state $s^{\prime}$ according to the following rule:

$$
s^{\prime}= \begin{cases}\hat{s}^{\prime} & \text { if } \quad \mathbb{E}\left[V\left(\hat{s}^{\prime}\right) \mid \mathcal{I}(s)\right]-C\left(\hat{s}^{\prime}, s\right)>\mathbb{E}\left[V\left(\tilde{s}^{\prime}\right) \mid \mathcal{I}(s)\right] \\ \tilde{s}^{\prime} & \text { otherwise. }\end{cases}
$$

We now define the returns to schooling and the concept of the option value.

\subsection{Returns to Education}

We define the ex ante and ex post net returns to schooling. The net return (NR) to schooling includes per period earnings and costs associated with each educational choice and the option value of future opportunities (discussed in the next subsection). The ex ante net returns are defined before the unobservable components of future earnings are realized. They depend on agents' expectations and determine their choices. Standard methods for computing rates of return such as Mincer coefficients or internal rates of returns ignore costs and option values of future opportunities. They are only interpretable for terminal choices and ex post realized earnings streams $5_{5}^{5}$ We define the ex ante net return of $\hat{s}^{\prime}$ over $\tilde{s}^{\prime}$ for an agent currently in state $s$ as:

${ }^{5}$ See Heckman et al. (2006a) for a discussion of conventional methods for estimating rates of return and their economic interpretation. 


$$
\frac{\mathbb{E}\left[V\left(\hat{s}^{\prime}\right)-V\left(\tilde{s}^{\prime}\right) \mid \mathcal{I}(s)\right]-C\left(\hat{s}^{\prime}, s\right)}{\mathbb{E}\left[V\left(\tilde{s}^{\prime}\right) \mid \mathcal{I}(s)\right]}=N R^{a}\left(\hat{s}^{\prime}, \tilde{s}^{\prime}, s\right) .
$$

We also define the ex ante gross return $(G R)$ which includes all future earnings, but omits all costs related to educational choices. Define the gross value of a state $s$ recursively as:

$$
\tilde{V}(s)=Y(s)+\frac{1}{1+r}\left(\mathbb{E}\left[\tilde{V}\left(s^{\prime}\right) \mid \mathcal{I}(s)\right]\right)
$$

where state $s^{\prime} \in \Omega(s)$ maximizes the discounted future rewards according to the policy function defined in equation (6). Although agents do not base their educational choices upon the gross returns, they are important as they are defined in terms of earnings streams only and are the focus of much applied work reporting rates of return. We define the ex ante gross return of $\hat{s}^{\prime}$ over $\tilde{s}^{\prime}$ for an agent in $s$ as:

$$
\frac{\mathbb{E}\left[\tilde{V}\left(\hat{s}^{\prime}\right)-\tilde{V}\left(\tilde{s}^{\prime}\right) \mid \mathcal{I}(s)\right]}{\mathbb{E}\left[\tilde{V}\left(\tilde{s}^{\prime}\right) \mid \mathcal{I}(s)\right]}=G R^{a}\left(\hat{s}^{\prime}, \tilde{s}^{\prime}, s\right) .
$$

We formulate the net and gross ex post returns in the same way but use the value functions which include the realizations of the earnings shock. The ex post returns can be used to evaluate an agent's regret of his educational choice.

\subsection{Option Values of Schooling}

Consider a high school enrollee who is contemplating whether to either graduate or drop out. Part of his evaluation of the benefits of high school graduation is the option to start college. From the perspective of state $s$ the option value of $s^{\prime}$ is defined as the difference between the value of taking the optimal choice when moving from $s^{\prime}$ and the fallback value of the zero cost exit $\tilde{s}^{\prime \prime}$. The zero cost exit is usually associated with maintaining the current education level, e.g. remaining a high school graduate and not enrolling in college. Then the option value ${ }^{6}$ of feasible state $s^{\prime}$ from the perspective of $s$ is:

¿Weisbrod (1962) was the first to analyze option values in the context of schooling and human capital accumulation. 


$$
\begin{gathered}
O V\left(s^{\prime}, s\right)= \\
=\frac{1}{1+r} \mathbb{E}\left[\mathbb{E}\left[\max _{s^{\prime \prime} \in \Omega\left(s^{\prime}\right)}\left\{V\left(s^{\prime \prime}\right)-C\left(s^{\prime \prime}, s^{\prime}\right)\right\} \mid \mathcal{I}\left(s^{\prime}\right)\right]-\mathbb{E}\left[V\left(\tilde{s}^{\prime \prime}\right) \mid \mathcal{I}\left(s^{\prime}\right)\right] \mid \mathcal{I}(s)\right] \\
=\frac{1}{1+r} \mathbb{E}[\underbrace{\max _{s^{\prime \prime} \in \Omega\left(s^{\prime}\right)}\left\{V\left(s^{\prime \prime}\right)-C\left(s^{\prime \prime}, s^{\prime}\right)\right\}}_{\text {value of options arising from } s^{\prime}}-\underbrace{V\left(\tilde{s}^{\prime \prime}\right)}_{\text {fallback value }} \mid \mathcal{I}(s)] .
\end{gathered}
$$

We define the option value contribution $O V C\left(s^{\prime}, s\right)=\frac{O V\left(s^{\prime}, s\right)}{\mathbb{E}\left[V\left(s^{\prime}\right) \mid \mathcal{I}(s)\right]}$ as the relative share of the option value in the overall value of a state. This component is not reported in standard calculations of the Mincer return or the internal rate of return.

\subsection{Identification}

Our model is semi-parametrically identified using a straightforward extension of the arguments in Heckman and Navarro (2007). The main arguments of the proof, presented in Web Appendix A, consist of using: (1) a limit set argument to identify the joint distribution of earnings and measurements free of selection ("identification at infinity"), (2) the measurement system on the factor structure that facilitates identification of the joint distribution of factors, (3) the choice structure and exclusion restrictions to identify the distribution of costs in the last choice equation, and (4) backward induction to identify relevant distributions in all states showing that the future value function acts as an exclusion restriction in current choices. We can identify all of the parameters of the model including the discount rate. 


\section{Baseline Estimates}

We fit the model on a sample of 1,418 white males from the National Longitudinal Survey of Youth of 1979 (NLSY79) using ML estimation.77 Figure 1 shows the decision tree for our model.

Figure 1: Decision Tree

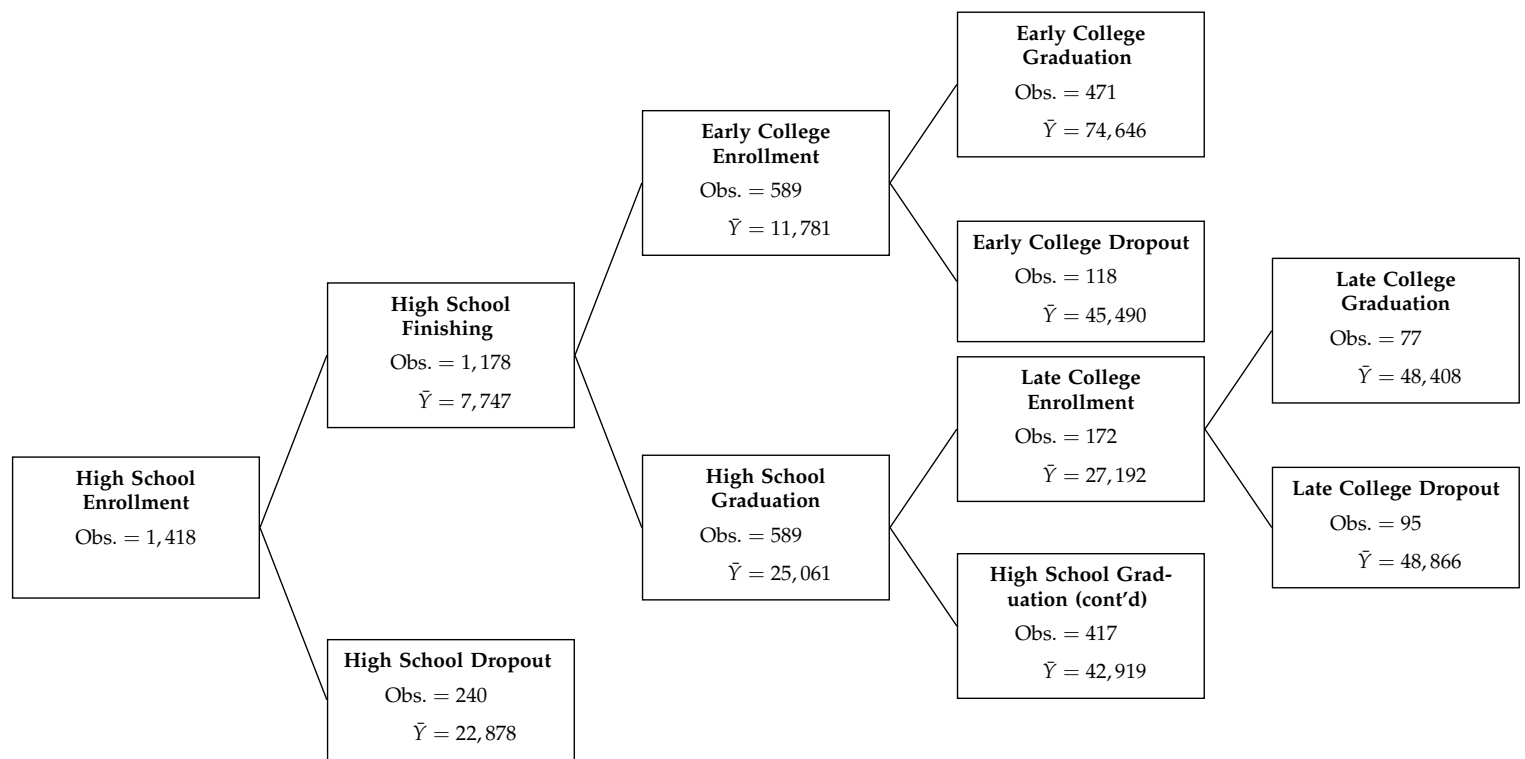

Notes: $\bar{Y}$ refers to average annual earnings in the state in 2005 \$. Obs. refers to the number of observations in the state.

All agents start in high school and decide to either drop out or finish. If they finish high school, they can enroll in college immediately or remain high school graduates with the option to enroll in college later or not at all. Conditional on early or late college enrollment, agents can either graduate or drop out. At each decision node, we designate the lower transition to be the zero cost exit. Our addition of the distinction between late and early enrollment is the only place in the model where time is introduced. We do this to improve the fit of the model and incorporate an important feature of the data on education.

For every state $s$, agents work in the labor market and receive earnings $Y(s)$. When agents pursue

${ }^{7}$ See Web Appendix B and Bureau of Labor Statistics (2001) for a description of our sample and the NLSY79. 
higher education by transitioning to the costly state $\hat{s}^{\prime}$, they incur $\operatorname{cost} C\left(\hat{s}^{\prime}, s\right)$. Agents face uncertainty about components of future earnings and costs when determining the ex ante value of each state $V(s)$ given the information available to them. As noted in Section 2, we assume that the agent knows his type and all past, present, and future covariates including local labor market conditions. His expectations about the distributions of all future shocks are assumed to be consistent with their actual realizations.

Following Carneiro et al. (2003) and Heckman et al. (2006b), we assume that the agent's type $\theta$ is summarized by cognitive and non-cognitive abilities. We use the scores on the Armed Services Vocational Aptitude Battery (ASVAB) as noisy measures on cognitive abilities. For non-cognitive skills, we rely on Rotter and Rosenberg 1980 scores and indicators of risky behaviors such as drug and alcohol use.

In a state $s$, we assign each agent a duration $D(s)$ based on the number of periods spent in that state. For an agent who spent four years in college, the duration of the college enrollment state will be four. We set the duration for an agent's counterfactual state to the median duration among the agents who actually visit that state. Let $Y(t, s)$ denote the observed earnings in the NLSY79 at time $t$ for an agent in state $s$. We collapse all $Y(t, s)$ within state $s$ into one discounted average.

$$
Y(s)=\frac{\sum_{t=1}^{D(s)}\left(\frac{1}{1+r}\right)^{t-1} Y(t, s)}{\sum_{t=1}^{D(s)}\left(\frac{1}{1+r}\right)^{t-1}} .
$$

We do the same for time varying covariates in $X(s)$ and $Q\left(\hat{s}^{\prime}, s\right)$. This setup differs from standard dynamic discrete choice models as the timing of earnings within each state does not matter. We do not estimate the discount factor $r$ and instead set $r=0.048$

We discuss the construction of our sample in Web Appendix B. The NLSY79 only has data up to approximately age 45 . We extend the duration of the terminal states up to age 65 using parameters estimated on the available sample to project earnings in unobserved years. The high school enrollment state characterizes initial conditions in our model. We assume earnings and costs are functions of

\footnotetext{
${ }^{8}$ Heckman and Navarro (2007) and Web Appendix A present conditions under which $r$ is identified.
} 
standard individual characteristics and local economic conditions 9

Figure 1 presents the average annual earnings and the number of observations by state. Earnings are low during the year of graduation $(\$ 7,747)$. High school graduates earn $(\$ 42,919)$ which is almost twice as much as high school dropouts $(\$ 22,878)$. Our distinction between early and late college enrollment is important. Early enrollees earn much less while in college $(\$ 11,781)$ compared to late enrollees $(\$ 27,192)$. Also, early college graduation boosts average annual earnings to $\$ 74,646$ compared to only $\$ 48,408$ for late graduation. In the case of late college enrollment, the difference in earnings among graduates and dropouts is minor: $\$ 48,408$ compared to $\$ 48,866$. This explains why in our sample the number of late college dropouts (95) is actually larger than of late college graduates (77). For the case of early enrollment (589), the vast majority graduates (471). The Mincer coefficient is $0.116{ }^{10}$

\subsection{Model Fit}

Table 1 shows the fit of the model estimated by ML for model fit statistics that are typically used in the literature. Average earnings and state frequencies are well fit by our model. Small discrepancies

${ }^{9}$ In each state, earnings depend on the number of children in the household, parental education (as the maximum between the mother's and father's education), indicators for the presence of a baby (child less than 3 years old) in the household, marriage status, urban residence at age 14, the region of residence (North East, North Central, South, and West), hourly wage and unemployment levels in the state of residence for the relevant age group (we use two age groups, younger than 30 years old or older). For the cost equations we exclude the indicator for marriage and the regional dummies, adding instead an indicator for whether the family is intact or not, the number of siblings, and state level tuitions for public two- and four-year colleges for the transitions to college enrollment states. The state representing the conclusion of high school is estimated using only an intercept, the two factors, and an unobservable component. All transition and outcome equations also include the cognitive and non-cognitive factor and an idiosyncratic unobserved component.

${ }^{10} \mathrm{Web}$ Appendix $\mathrm{C}$ presents additional descriptive statistics and estimates of conventional internal rates of return. 
show up for terminal states. Terminal states are populated by very few agents, which requires us to constrain the outcome and cost parameters of terminal college states to be the same for early and late transitions.

Table 1: Cross Section Model Fit

\begin{tabular}{lcccc}
\hline & \multicolumn{3}{c}{ Average Earnings } & \multicolumn{2}{c}{ State Frequencies } \\
State & Observed & ML & Observed & ML \\
\hline High School Finishing & 0.77 & 0.78 & 0.83 & 0.86 \\
High School Dropout & 2.29 & 2.57 & 0.17 & 0.14 \\
Early College Enrollment & 1.18 & 1.40 & 0.42 & 0.40 \\
High School Graduation & 2.51 & 2.48 & 0.42 & 0.45 \\
Early College Graduation & 7.47 & 6.77 & 0.33 & 0.29 \\
Early College Dropout & 4.55 & 3.84 & 0.08 & 0.11 \\
Late College Enrollment & 2.72 & 2.54 & 0.12 & 0.14 \\
High School Graduation (cont'd) & 4.29 & 3.83 & 0.29 & 0.32 \\
$\begin{array}{l}\text { Late College Graduation } \\
\text { Late College Dropout }\end{array}$ & 4.84 & 6.16 & 0.05 & 0.08 \\
\hline $\begin{array}{l}\text { Notes: Earnings are discounted using the within state duration and measured in units of } \$ 10,000 . \\
\text { Statistics are calculated on the NLSY79 sample and for ML based on 50,000 simulated agents using } \\
\text { the parameter estimates. State frequencies are unconditional. }\end{array}$ & & &
\end{tabular}

Comparing the fit of the model to cross section moments is a weak criterion for a dynamic model. A more exacting criterion is to predict sequences of educational choices (Heckman, 1981). We follow Heckman and Walker (1990) and Heckman (1984) and use $\chi^{2}$ goodness of fit tests to examine our model's performance. In Table 2 we report the $p$-value of a joint test of the relative share of agents for each state for all realizations of selected covariates ${ }^{11}$ For most cells the fit is good.

${ }^{11}$ In the $\chi^{2}$ test, the predicted covariate distributions depends on estimated parameters. We do not adjust the test statistic to account for parameter estimation error as suggested by Heckman (1984) 
Table 2: Conditional Model Fit

\begin{tabular}{lcccc}
\hline State & Number of Children & Baby in Household & Parental Education & Broken Home \\
\hline High School Dropout & 0.77 & 0.26 & 0.37 & 0.03 \\
High School Finishing & 0.88 & 0.73 & 0.55 & 0.35 \\
High School Graduation & 0.91 & 0.94 & 0.65 & 0.91 \\
High School Graduation (cont'd) & 0.95 & 0.33 & 0.40 & 0.85 \\
Early College Enrollment & 0.46 & 0.54 & 0.01 & 0.15 \\
Early College Graduation & 0.06 & 0.86 & 0.00 & 0.14 \\
Early College Dropout & 0.33 & 0.27 & 0.54 & 0.75 \\
Late College Enrollment & 0.80 & 0.23 & 0.90 & 0.60 \\
Late College Graduation & 0.90 & 0.39 & 0.90 & 0.60 \\
Late College Dropout & 0.89 & 0.42 & 0.91 & 0.76 \\
\hline
\end{tabular}

One exception (at a 5\% significance level) is Parental Education, where we fail to fit the observed patterns for early college enrollment and early college graduation. For Broken Home, we overpredict the relative share of individuals from a broken home among high school dropouts. For all other variables and states, the $p$-values indicate that the model is consistent with the data. Because tests within covariates across all states are not independent, we use a Bonferroni test to evaluate the joint hypothesis that the predicted covariate distributions fit at each state. The test is based on the maximum $\chi^{2}$ statistic over all states for each covariate. A 5\% Bonferroni test is passed by all covariates besides Parental Education. Here, the poor prediction for early college graduates leads to an overall rejection.

\subsection{Economic Implications}

We now present the economic implications of our baseline results. We first discuss the impact of unobserved abilities on educational choices and earnings and then turn to the role of psychic costs and option values for the net returns to schooling. We conclude with a counterfactual policy evaluation.

because the adjustments are usually slight (Heckman and Walker, 1990). 


\subsubsection{Impact of Abilities}

Figure 2 shows the share of agents in each of the final states by deciles of the overall factor distribution. The distributions of abilities differ substantially across schooling outcomes. Early college graduates $\left(C O E_{E}\right)$ are strong in cognitive and non-cognitive abilities. High school dropouts $(H S D)$ are weak in both. High school graduates who never enroll in college (HSG) are weak in cognitive abilities but quite strong in non-cognitive abilities.

Figure 2: Ability Distributions by Final Education

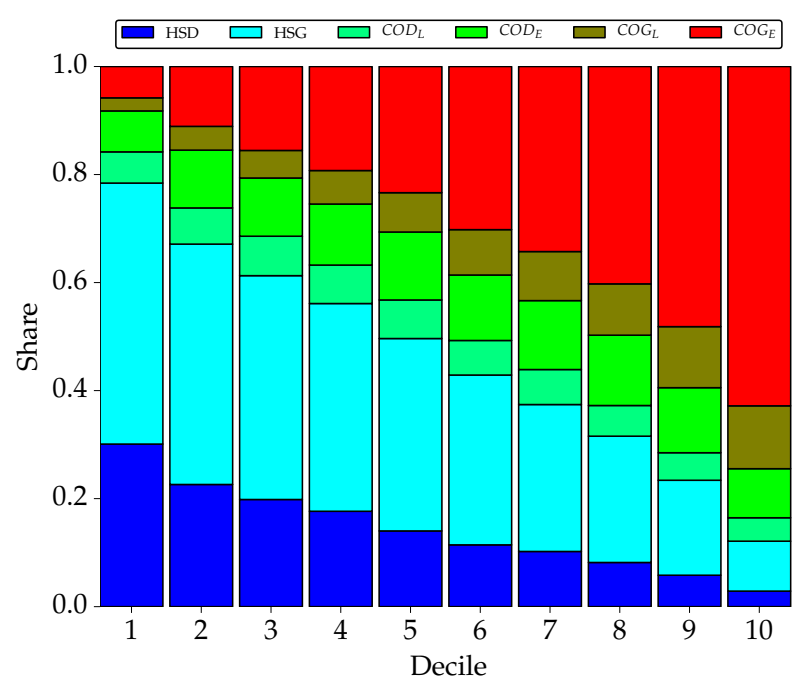

(a) Cognitive

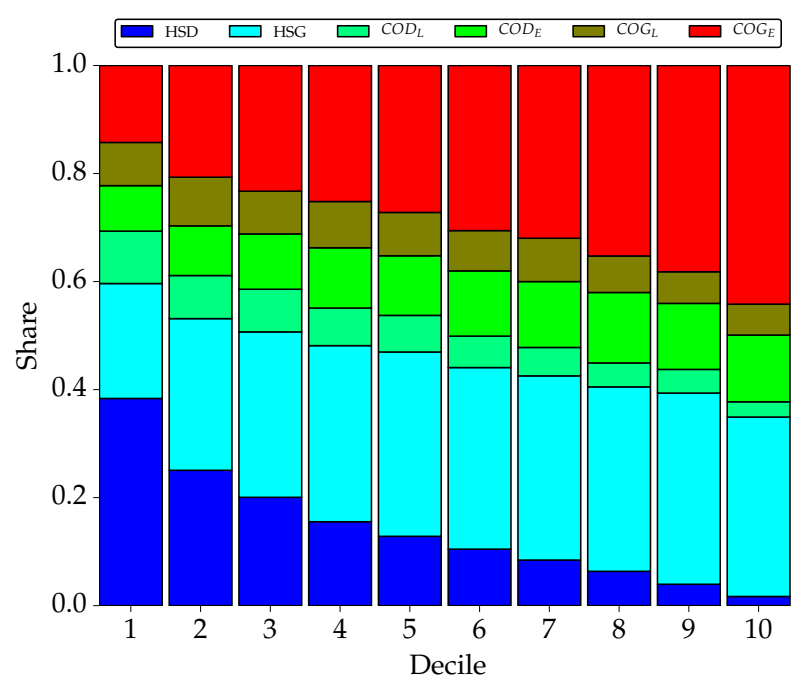

(b) Non-cognitive

Notes: We simulate a sample of 50,000 agents based on the estimates of the model.

Figure 3 shows the transition probabilities to each state by factor deciles. Higher cognitive skills increase the likelihood of continued educational achievement for all choices. The effect of non-cognitive abilities is mixed. While they clearly increase the likelihood of finishing high school, higher noncognitive skills decrease the probability of late college enrollment (conditional on working after high school graduation). Delay of college enrollment is associated with lower levels of non-cognitive skills.

\subsubsection{Returns to Education}

Figure 4 presents the ex ante net return to schooling by factor deciles. The effect of latent skills on returns differs by state. The return of finishing high school is strongly affected by the non-cognitive 
factor. Usually the effect of cognitive skills is more pronounced. Nevertheless, our estimates show evidence of strong complementarity between abilities and schooling for most states. Figure 4 also presents median returns. The median net return for early college enrollment is around zero and the return of delayed enrollment even negative $(-21 \%)$. College dropouts pay the cost of college without benefiting from the much larger returns of graduating. The returns from graduating late $(10 \%)$ are much smaller than for those graduating early (50\%). We report the difference between net and gross returns as part of Figure 4 .

Psychic costs are crucial determinants of net returns. For example, the median gross return for early and late college enrollment is positive, while the median net return is negative in both cases. As only agents with a positive net return choose to continue their education, this follows directly from our estimates (and the data) as more than half of the agents that are faced with the decision to enroll in college refrain from doing so.

We estimate the overall costs associated with each educational choice. Our estimated costs combine monetary expenses such as tuition and psychic costs. Table 3 reports the average costs associated with each transition. It reports the second, fifth, and eighth decile of their distribution to document their substantial heterogeneity. Costs are key components of the net returns, ignoring them results in strongly biased estimates. The largest costs are associated with early and late college enrollment. These are the only states with psychic as well as monetary costs from tuition. Enrolling early costs the equivalent of $\$ 273,000$ compared to $\$ 553,000$ for late enrollment. At least $20 \%$ of agents have negative schooling costs in most states. They experience psychic benefits. For high school graduation, even the average cost is negative. Psychic costs play a dominant role in explaining schooling decisions. This is an unsatisfactory feature of the models in the literature (see e.g. Cunha et al. (2005), Abbott et al. (2013)). 
Table 3: Costs

\begin{tabular}{lllll}
\hline State & Mean & $2^{\text {nd }}$ Decile & $5^{\text {th }}$ Decile & $8^{\text {th }}$ Decile \\
\hline High School Finishing & $-2.38^{* *}$ & $-5.52^{* * *}$ & $-2.40^{* *}$ & $0.79^{*}$ \\
Early College Enrollment & 2.73 & -0.65 & 2.69 & 6.10 \\
Early College Graduation & 1.82 & -3.88 & 1.89 & 7.61 \\
Late College Enrollment & $5.53^{* *}$ & 1.72 & $5.48^{* *}$ & $9.37^{* *}$ \\
Late College Graduation & 1.13 & -4.72 & 1.35 & 7.32 \\
\hline
\end{tabular}

Notes: We simulate a sample of 50,000 agents based on the estimates of the model. We condition on the agents that actually visit the relevant decision state. Costs are in units of $\$ 100,000$. We determine the accuracy of our estimates using the simulation approach proposed by Krinsky and Robb 1986. 1990 with 1,200 replications. Level of Significance: ${ }^{* * *} 1 \%, * * 5 \%, * 10 \%$.

Ex ante and ex post returns do not necessarily agree because agents cannot predict their future earnings. Decisions that are optimal for an agent ex ante might be suboptimal ex post. For this reason, we calculate the percentage of agents experiencing regret, i.e., those agents for whom the ex post and ex ante returns do not agree in sign ${ }^{12}$ A substantial share of late college enrollees (34\%) regret the decision to graduate. For finishing high school, the share is much smaller (4\%). However, $24 \%$ of high school dropouts regret their decision.

\subsubsection{Option Values of Schooling}

Our structural model allows us to calculate the option values of educational choices ${ }^{13}$ We defined the option value in equation (9) as the difference in the value associated with the optimal continuation of choices versus the fallback value. Figure 5 shows the option values conditional on the deciles of the

\footnotetext{
${ }^{12}$ See Web Appendix $\mathrm{C}$ for additional results on ex post returns and regret.

${ }^{13}$ Other models taking into account option values have been proposed by Comay et al. (1973), Cunha et al. (2007), Heckman et al. (2014a), and Trachter (2014). See also Cameron and Heckman (1993).
} 
factor distributions, their median $(O V)$, and their contribution to the total value of each state (OVC). The option values make a sizable contribution to the overall value of the states and vary by abilities.

Early college enrollment has the highest option value as graduation yields a large gain in earnings compared to dropping out. As the net returns to college graduation increase in cognitive and noncognitive abilities, so does the option value of college enrollment.

\subsubsection{Policy Analysis}

Counterfactual policy analysis is one of the main motivations for the estimation of dynamic structural models (Wolpin, 2013). We investigate the impact of a 50\% reduction in tuition cost on agents' college going decisions. We simulate 50,000 agents from our model and compare their educational choices under the baseline regime and the policy alternative. Agents are forward-looking and due to the sequential decision tree, reducing tuition for college attendance already increases high school graduation rates by one percentage point as its option value increases. Overall college enrollment increases by roughly ten percentage points as many high school graduates now decide to enroll in college. The increase is evenly split between early and late enrollment. However, there are considerable differences in graduation rates among those induced to enter into college depending on the time of enrollment. About half of the new early enrollees will eventually graduate, while only a quarter of the late enrollees will do so as well. 
Figure 3: Transition Probabilities by Abilities

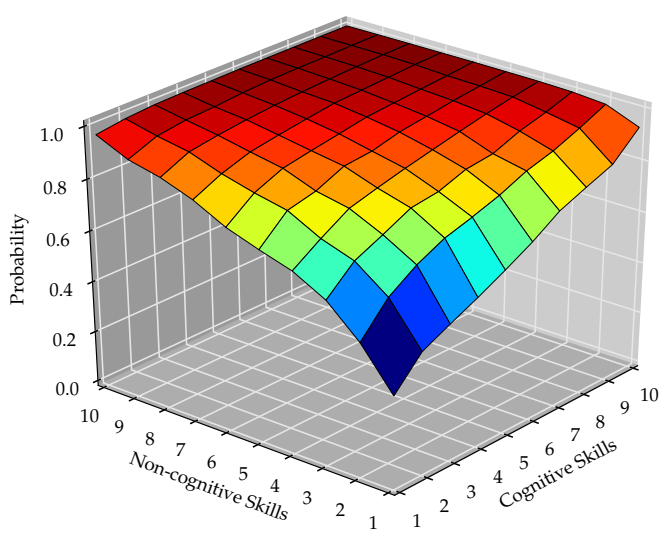

(a) High School Finishing

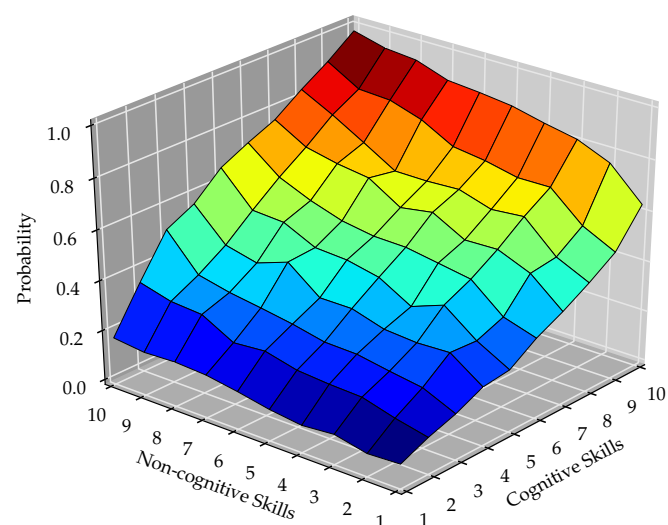

(b) Early College Enrollment

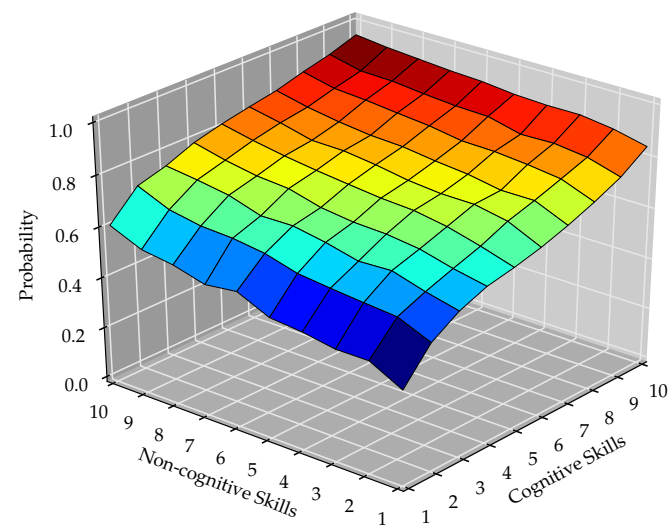

(c) Early College Graduation

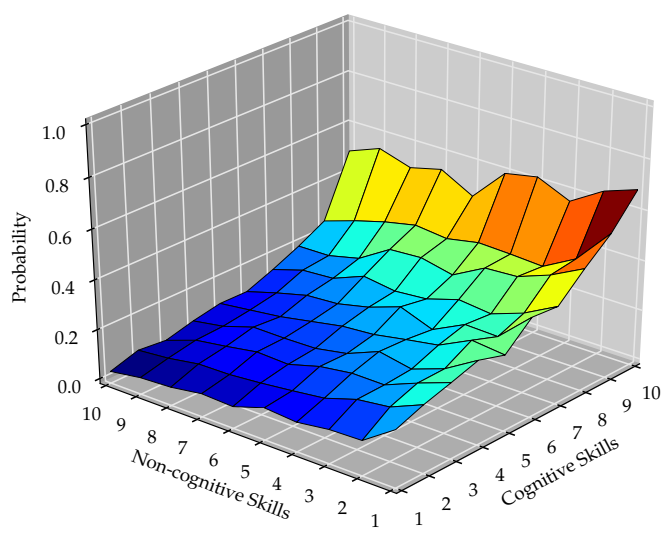

(d) Late College Enrollment

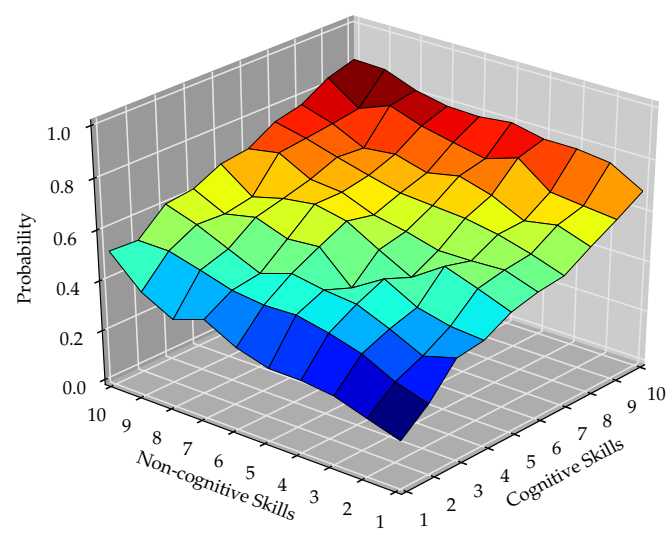

(e) Late College Graduation

Notes: We simulate a sample of 50,000 agents based on the estimates of the model. In each subfigure, we condition on the agents that actually visit the relevant decision state. 
Figure 4: Ex Ante Net Returns by Abilities

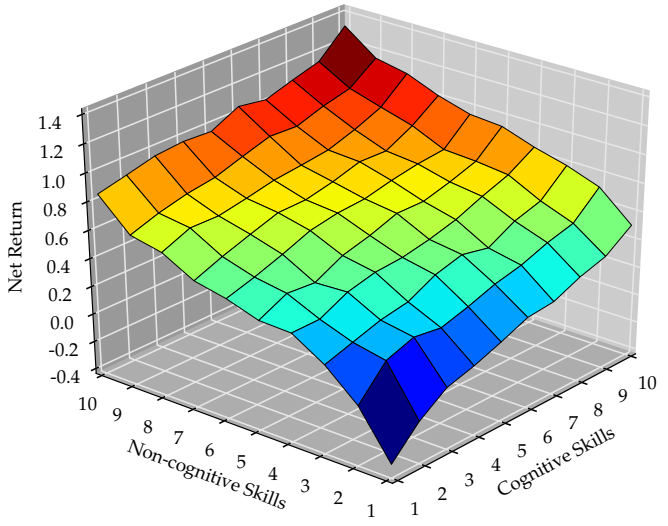

(a)

High School Finishing $N R^{a}=0.64$
$G R^{a}=0.27$

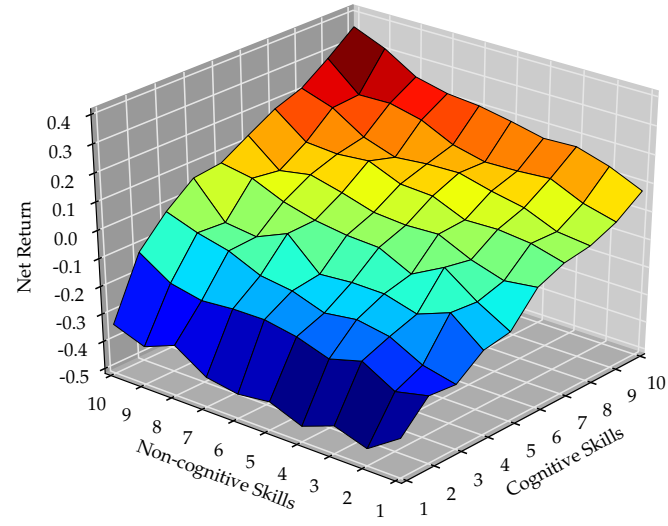

(b) $N R^{a}=-0.03$ $G R^{a}=0.14$

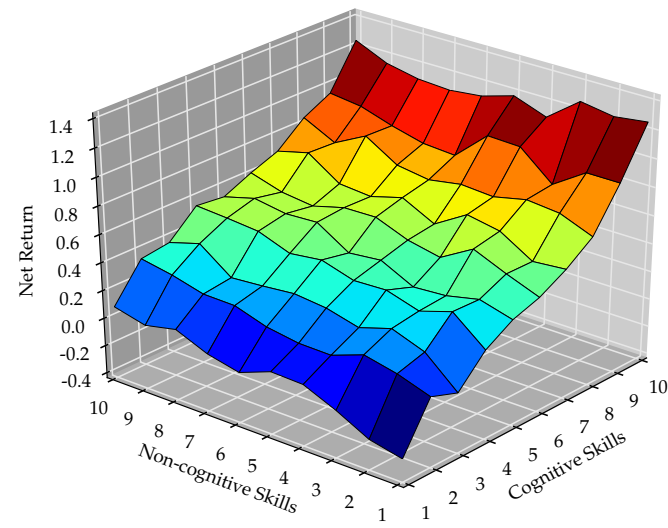

(c)

Early College Graduation $N R^{a}=0.50$

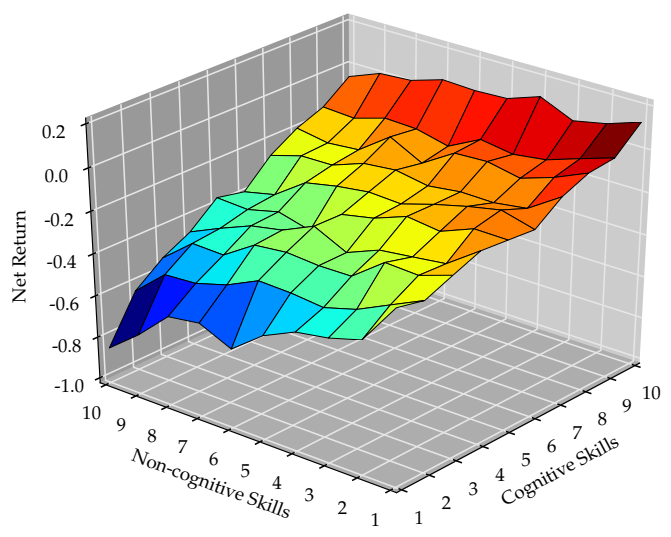

(d)

Late College Enrollment $N R^{a}=-0.21$
$G R^{a}=0.29$

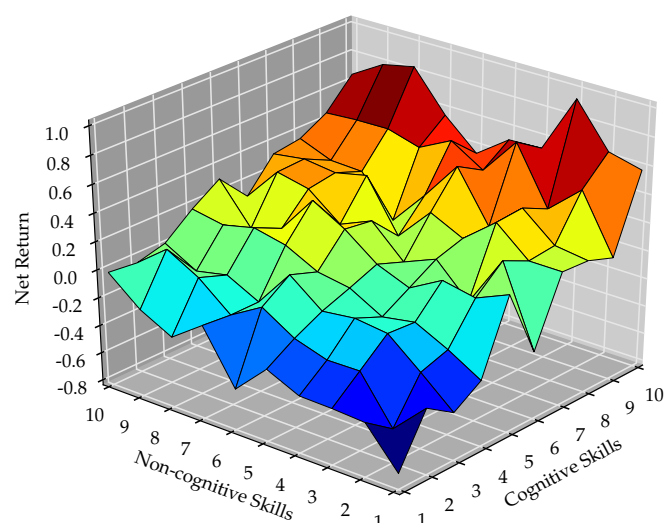

(e)

Late College Graduation $N R^{a}=0.10$
$G R^{a}=0.24$

Notes: We simulate a sample of 50,000 agents based on the estimates of the model. In each subfigure, we condition on the agents that actually visit the relevant decision state. 
Figure 5: Option Values by Abilities

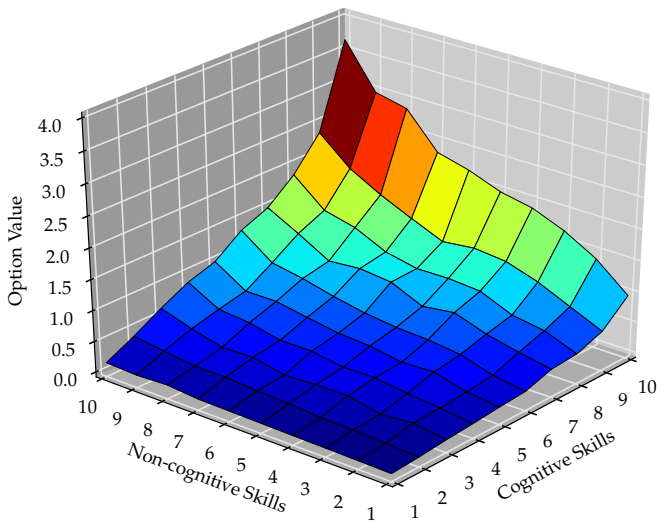

(a)

High School Finishing

$$
\begin{aligned}
& O V=0.52 \\
& O V C=0.07
\end{aligned}
$$

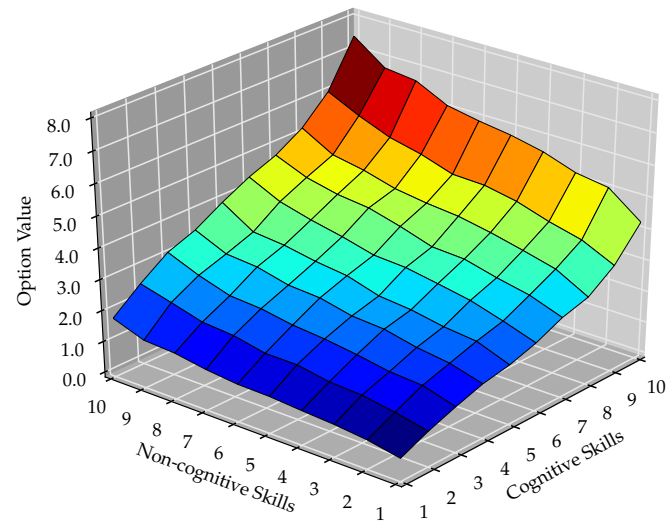

(b)

Early College Enrollment

$$
\begin{aligned}
& O V=3.06 \\
& O V C=0.30
\end{aligned}
$$

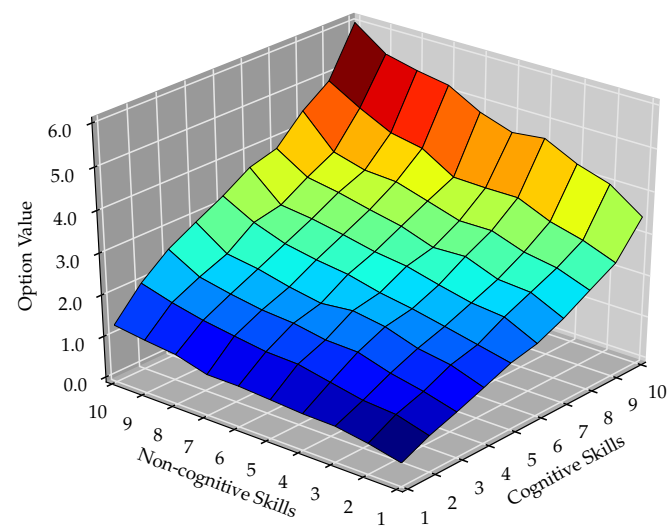

(c)

Late College Enrollment

$O V=1.87$

$O V C=0.17$

Notes: We simulate a sample of 50,000 agents based on the estimates of the model. In each subfigure, we condition on the agents that actually visit the relevant decision state. In units of $\$ 100,000$. 


\section{Comparison of ML and SMM}

We use the baseline estimates of our structural parameters to simulate a synthetic sample of 5,000 agents. This sample captures important aspects of our original data such as model complexity and sizable unobserved variation in agent behaviors. We disregard our knowledge about the true structural parameters and estimate the model on the synthetic sample by ML and SMM to compare their performance in recovering the true structural objects. We first describe the implementation of both estimation procedures. Then we compare their within-sample model fit and assess the accuracy of the estimated returns to education and policy predictions. Finally, we explore the sensitivity of our SMM results to alternative tuning parameters such as choice of the moments, number of replications, weighting matrix, and optimization algorithm.

We assume the same functional forms and distributions of unobservables for ML and SMM. Measurement, outcome, and cost equations (1) - (3) are linear-in-parameters. Recall that $S^{c}$ denotes the subset of states with a costly exit.

$$
\begin{array}{lll}
M(j) & =X(j)^{\prime} \kappa_{j}+\theta^{\prime} \gamma_{j}+v(j) & \forall j \in M \\
Y(s) & =X(s)^{\prime} \beta_{s}+\theta^{\prime} \alpha_{s}+\epsilon(s) & \forall s \in \mathcal{S} \\
C\left(\hat{s}^{\prime}, s\right)=Q\left(\hat{s}^{\prime}, s\right)^{\prime} \delta_{\hat{s}^{\prime}, s}+\theta^{\prime} \varphi_{\hat{s}^{\prime}, s}+\eta\left(\hat{s}^{\prime}, s\right) & \forall s \in \mathcal{S}^{c}
\end{array}
$$

All unobservables of the model are normally distributed:

$$
\begin{aligned}
\eta\left(\hat{s}^{\prime}, s\right) & \sim \mathcal{N}\left(0, \sigma_{\eta\left(\hat{s}^{\prime}, s\right)}\right) & \forall s \in \mathcal{S}^{c} & \epsilon(s) & \sim \mathcal{N}\left(0, \sigma_{\epsilon(s)}\right) \quad \forall s \in \mathcal{S} \\
\theta & \sim \mathcal{N}\left(0, \sigma_{\theta}\right) & \forall \theta \in \Theta & v(j) & \sim \mathcal{N}\left(0, \sigma_{v(j)}\right) \quad \forall j \in \mathcal{M} .
\end{aligned}
$$

The unobservables $\left(\epsilon(s), \eta\left(\hat{s}^{\prime}, s\right), v(j)\right)$ are independent across states and measures. The two factors $\theta$ are independently distributed. This still allows for unobservable correlations in outcomes and choices through the factor components $\theta$ (Cunha et al., 2005).

\subsection{The ML Approach}

We now describe the likelihood function, its implementation, and the optimization procedure. 
For each agent we define an indicator function $G(s)$ that takes value one if the agent visits state $s$. Let $\psi \in \Psi$ denote a vector of structural parameters and $\Gamma$ the subset of states visited by agent $i$. We collect in $D=\left\{\{X(j)\}_{j \in M},\left\{X(s), Q\left(\hat{s}^{\prime}, s\right)\right\}_{s \in S}\right\}$ all observed agent characteristics. Then the likelihood for observation $i$ is given by

$$
\int_{\underline{\Theta}}[\prod_{j \in M} \underbrace{f(M(j) \mid D, \theta ; \psi)}_{\text {Measurement }} \prod_{s \in \mathcal{S}}\{\underbrace{f(Y(s) \mid D, \theta ; \psi)}_{\text {Outcome }} \underbrace{\operatorname{Pr}(G(s)=1 \mid D, \theta ; \psi)}_{\text {Transition }}\}^{\mathbb{1}\{s \in \Gamma\}}] d F(\theta)
$$

where $\underline{\Theta}$ is the support of $\theta$. After taking the logarithm of equation $(10)$ and summing across all agents, we obtain the sample log likelihood.

Let $\phi_{\sigma}(\cdot)$ denote the probability density function and $\Phi_{\sigma}(\cdot)$ the cumulative distribution function of a normal distribution with mean zero and variance $\sigma$. The density functions for measurement and earning equations take a standard form conditional on the factors and other relevant observables:

$$
\begin{aligned}
& f(M(j) \mid \theta, X(j))=\phi_{\sigma_{v(j)}}\left(M(j)-X(j)^{\prime} \kappa_{j}-\theta^{\prime} \gamma_{j}\right) \quad \forall j \in M \\
& f(Y(s) \mid \theta, X(s))=\phi_{\sigma_{\epsilon(s)}}\left(Y(s)-X(s)^{\prime} \beta_{s}-\theta^{\prime} \alpha_{s}\right) \quad \forall s \in \mathcal{S} .
\end{aligned}
$$

The derivation of the transition probabilities has to account for forward-looking agents who make their educational choices based on the current costs and expectations of future rewards. Agents know the full cost of the next transition and the systematic parts of all future earnings and costs $\left(X(s)^{\prime} \beta_{s}, Q\left(\hat{s}^{\prime}, s\right)^{\prime} \delta_{\hat{s}^{\prime}, s}\right)$. They do not know the values of future random shocks. Agents at state $s$ decide whether to transition to the costly state $\hat{s}^{\prime}$ or the no-cost alternative $\tilde{s}^{\prime}$. Their ex ante valuations $T\left(s^{\prime}\right)$ incorporate expected earnings and costs, and the continuation value $C V\left(s^{\prime}\right)$ from future opportunities. Given our functional form assumptions, the ex ante value of state $s^{\prime}$ is:

$$
T\left(s^{\prime}\right)= \begin{cases}X^{\prime}\left(\hat{s}^{\prime}\right) \beta_{\hat{s}^{\prime}}+\theta^{\prime} \alpha_{\hat{s}^{\prime}}-Q\left(\hat{s}^{\prime}, s\right)^{\prime} \delta_{\hat{s}^{\prime}, s}-\theta^{\prime} \varphi_{\hat{s}^{\prime}, s}+C V\left(\hat{s}^{\prime}\right) & \text { if } \quad s^{\prime}=\hat{s}^{\prime} \\ X^{\prime}\left(\tilde{s}^{\prime}\right) \beta_{\tilde{s}^{\prime}}+\theta^{\prime} \alpha_{\tilde{s}^{\prime}}+C V\left(\tilde{s}^{\prime}\right) & \text { if } \quad s^{\prime}=\tilde{s}^{\prime}\end{cases}
$$


The ex ante state evaluations and distributional assumptions characterize the transition probabilities:

$$
\operatorname{Pr}\left(G\left(s^{\prime}\right)=1 \mid D, \theta ; \psi\right)= \begin{cases}\Phi_{\sigma_{\eta\left(\hat{s}^{\prime}, s\right)}\left(T\left(\hat{s}^{\prime}\right)-T\left(\tilde{s}^{\prime}\right)\right)} & \text { if } \quad s^{\prime}=\hat{s}^{\prime} \\ 1-\Phi_{\sigma_{\eta\left(s^{\prime}, s\right)}}\left(T\left(\hat{s}^{\prime}\right)-T\left(\tilde{s}^{\prime}\right)\right) & \text { if } \quad s^{\prime}=\tilde{s}^{\prime}\end{cases}
$$

Finally, the continuation value of $s$ is:

$$
\begin{aligned}
C V(s) & =\left[\Phi_{\sigma_{\eta\left(\hat{s}^{\prime}, s\right)}}\left(T\left(\hat{s}^{\prime}\right)-T\left(\tilde{s}^{\prime}\right)\right)\right] \times \int_{-\infty}^{T\left(\hat{s}^{\prime}\right)-T\left(\tilde{s}^{\prime}\right)}\left[T\left(\hat{s}^{\prime}\right)-\eta\right] \frac{\phi_{\sigma_{\eta\left(\hat{s}^{\prime}, s\right.}}(\eta)}{\Phi_{\sigma_{\eta\left(\hat{s}^{\prime}, s\right)}}\left(T\left(\hat{s}^{\prime}\right)-T\left(\tilde{s}^{\prime}\right)\right)} \mathrm{d} \eta \\
& +\left[1-\Phi_{\sigma_{\eta\left(\hat{s}^{\prime}, s\right)}}\left(T\left(\hat{s}^{\prime}\right)-T\left(\tilde{s}^{\prime}\right)\right)\right] \times T\left(\tilde{s}^{\prime}\right),
\end{aligned}
$$

where we integrate over the conditional distribution of $\eta\left(\hat{s}^{\prime}, s\right)$ as the agent chooses the costly transition to $\hat{s}^{\prime}$ only if $T\left(\hat{s}^{\prime}\right)-\eta\left(\hat{s}^{\prime}, s\right)>T\left(\tilde{s}^{\prime}\right)$.

We compare ML against SMM for statistical and numerical reasons. ML estimation is fully efficient as it achieves the Cramér-Rao lower bound. The numerical precision of the overall likelihood function is very high with accuracy up to 15 decimal places. This guarantees at least three digits of accuracy for all estimated model parameters. We discuss the numerical properties of the likelihood and bounds on approximation error in Web Appendix Dand E. We use Gaussian quadrature to evaluate the integrals of the model ${ }^{14}$ We maximize the sample log likelihood using the Broyden-Fletcher-Goldfarb-Shanno (BFGS) algorithm (Press et al., 1992).

\subsection{The SMM Approach}

We present the basic idea of the SMM approach and the details of the criterion function. Then we discuss the choice of tuning parameters. The goal in the SMM approach is to choose a set of structural parameters $\psi$ to minimize the weighted distance between selected moments from the observed sample

\footnotetext{
${ }^{14}$ See Judd and Skrainka (2011) for a comparison of alternative integration strategies.
} 
and a sample simulated from a structural model. The criterion function takes the following form:

$$
\Lambda(\psi)=[\check{f}-\hat{f}(\psi)]^{\prime} W^{-1}[\check{f}-\hat{f}(\psi)]
$$

where $\check{f}$ represents a vector of moments computed on the observed data and $\hat{f}(\psi)$ denotes an average vector of moments calculated from $R$ simulated datasets and $W$ is a positive definite weighting matrix. We define $\hat{f}(\psi)$ as:

$$
\hat{f}(\psi)=\frac{1}{R} \sum_{r=1}^{R} \hat{f}_{r}\left(u_{r} ; \psi\right) .
$$

The simulation of the model involves the repeated sampling of the unobserved components $u_{r}=$ $\left\{\left\{\epsilon(s), \eta\left(\hat{s}^{\prime}, s\right)\right\}_{s \in S}\right\}$ determining agents' outcomes and choices. We repeat the simulation $R$ times for fixed $\psi$ to obtain an average vector of moments. $\hat{f}_{r}\left(u_{r} ; \psi\right)$ is the set of moments from a single simulated sample. We solve the model through backward induction and simulate 5,000 educational careers to compute each single set of moments. We keep the conditioning on exogenous agent characteristics implicit in equation (11).

We account for $\theta$ by estimating a vector of factor scores based on $M$ that proxy the latent skills for each participant (Bartlett, 1937). The scores are subsequently treated as ordinary regressors in the estimation of the auxiliary models. We use the true factors in the simulation steps, assuring that SMM and ML are correctly specified.

The random components $u_{r}$ are drawn at the beginning of the estimation procedure and remain fixed throughout. This avoids chatter in the simulation for alternative $\psi$, where changes in the criterion function could be due to either $\psi$ or $u_{r}$ (McFadden, 1989).

To implement our criterion function it is necessary to choose a set of moments, the number of replications, a weighting matrix, and an optimization algorithm. Later, we investigate the sensitivity of our results to these choices.

We select our set of moments in the spirit of the efficient method of moments (EMM), which provides a systematic approach to generate moment conditions for the generalized method of moments (GMM) estimator (Gallant and Tauchen, 1996). Gallant and Tauchen (1996) propose using the expec- 
tation under the structural model of the score from an auxiliary model as the vector of moment conditions. We do not directly implement EMM but follow a Wald approach instead, as we do not minimize the score of an auxiliary model but a quadratic form in the difference between the moments on the simulated and observed data. Nevertheless, we draw on the recent work by Heckman et al. (2014b) as an auxiliary model to motivate our moment choice ${ }^{15}$ Heckman et al. (2014b) develop a sequential schooling model that is a halfway house between a reduced form treatment effect model and a fully formulated dynamic discrete choice model such as ours. They approximate the underlying dynamics of the agents' schooling decisions by including observable determinants of future benefits and costs as regressors in current choice. We follow their example and specify these dynamic versions of Linear Probability (LP) models for each transition. In addition, we include mean and standard deviation of within state earnings and the parameters of Ordinary Least Squares (OLS) regressions of earnings on covariates to capture the within state benefits to educational choices. We add state frequencies as well. Overall, we start with a total 440 moments to estimate 138 free structural parameters.

We set the number of replications $R$ to 30 and thus simulate a total of 150,000 educational careers for each evaluation of the criterion function. The weighting matrix $W$ is a matrix with the variances of the moments on the diagonal and zero otherwise. We determine the latter by resampling the observed data 200 times. We exploit that our criterion function has the form of a standard nonlinear leastsquares problem in our optimization. Due to our choice of the weighting matrix, we can rewrite

${ }^{15}$ If the weighting matrices are appropriately chosen and the auxiliary model is correctly specified, then both approaches are asymptotically equivalent to ML (Gouriéroux et al., 1993). The EMM approach requires analytical derivatives for the auxiliary model, which is a very time-consuming, error-prone, and tedious task for large and complex models. For this reason, the EMM approach is not commonly used to estimate dynamic discrete choice models, but widely applied to fit stochastic volatility models. In the latter case, several tractable auxiliary models such as ARCH and GARCH are readily available (Andersen et al., 1999). See Carrasco and Florens (2002) for an accessible comparison of EMM to other simulation-based methods and additional references. 
equation (11) as:

$$
\Lambda(\psi)=\sum_{i=1}^{I}\left(\frac{\check{f}_{i}-\hat{f}_{i}(\psi)}{\hat{\sigma}_{i}}\right)^{2}
$$

where $I$ is the total number of moments, $f_{i}$ denotes moment $i$, and $\hat{\sigma}_{i}$ its bootstrapped standard deviation.

Our criterion is not a smooth function of the model parameters. Small changes in the structural parameters cause some simulated agents to change their educational choices, resulting in discrete jumps in our set of moments (Keane and Smith, 2003). Thus we cannot use gradient-based methods for optimization and rely on derivative-free alternatives instead. Moré and Wild (2009) show that modelbased solvers perform better than standard derivative-free direct search solvers used in the existing literature (see Adda et al. (2013, 2011) and Del Boca et al. (2014) for applications of derivative-free direct search solvers). From the class of model-based solvers, we choose the Practical Optimization Using No Derivatives for Sums of Squares (POUNDerS) algorithm (Munson et al., 2012). POUNDerS exploits the special structure of the nonlinear least-squares problem within a derivative-free trustregion framework and forms a smooth approximation model of the objective function to converge to a minimum 16

\subsection{Results}

We compare ML and SMM estimation to learn whether our version of SMM is a good substitute for ML. First, we compare basic model fit statistics. Second, we study the estimates for the returns to education and perform a counterfactual policy exercise. Finally, we explore alternative choices for the set of moments, weighting matrix, number of replications, and optimization algorithm.

${ }^{16}$ See Nocedal and Wright (2006) for a discussion of the nonlinear least-squares problem and Kortelainen et al. (2010) for a detailed description of the underlying mechanics of POUNDerS. 
Model Fit Table 4 shows the average annual earnings for each state and the conditional state frequencies. Overall, both estimation approaches fit these aggregate statistics quite well. The model fit for the average earnings among late college graduates and late college dropouts is slightly worse than for the other states as the agent count in those states is low. This affects the SMM estimates more than ML. The state frequencies are matched very well in both cases.

We report the root-mean-square error (RMSE) based on the difference between the simulated and observed statistics. There are only minor discrepancies for both estimation approaches. Nevertheless, they are slightly smaller for the ML results.

Table 4: Cross Section Model Fit

\begin{tabular}{|c|c|c|c|c|c|c|}
\hline \multirow[b]{2}{*}{ State } & \multicolumn{3}{|c|}{ Average Earnings } & \multicolumn{3}{|c|}{ State Frequencies } \\
\hline & Observed & ML & SMM & Observed & ML & SMM \\
\hline High School Finishing & 0.78 & 0.76 & 0.78 & 0.86 & 0.84 & 0.86 \\
\hline High School Dropout & 2.50 & 2.53 & 2.54 & 0.14 & 0.16 & 0.14 \\
\hline Early College Enrollment & 1.45 & 1.42 & 1.45 & 0.41 & 0.41 & 0.41 \\
\hline High School Graduation & 2.46 & 2.44 & 2.45 & 0.45 & 0.43 & 0.45 \\
\hline Early College Graduation & 6.81 & 6.99 & 6.67 & 0.29 & 0.30 & 0.29 \\
\hline Early College Dropout & 3.91 & 3.97 & 4.02 & 0.12 & 0.11 & 0.12 \\
\hline Late College Enrollment & 2.51 & 2.55 & 2.52 & 0.13 & 0.13 & 0.13 \\
\hline High School Graduation (cont'd) & 3.88 & 3.83 & 3.79 & 0.32 & 0.30 & 0.32 \\
\hline Late College Graduation & 6.03 & 6.21 & 6.19 & 0.07 & 0.07 & 0.07 \\
\hline \multirow[t]{2}{*}{ Late College Dropout } & 5.10 & 4.89 & 5.05 & 0.06 & 0.06 & 0.06 \\
\hline & \multicolumn{3}{|c|}{$\mathrm{ML}$} & \multicolumn{3}{|c|}{ SMM } \\
\hline RMSE & \multicolumn{3}{|c|}{0.05058} & \multicolumn{3}{|c|}{0.05748} \\
\hline
\end{tabular}

Notes: Earnings are discounted using the within state duration and measured in units of $\$ 10,000$. Statistics calculated for ML and SMM approaches based on 50,000 simulated agents using the parameter estimates. RMSE = root-meansquare error.

We apply $\chi^{2}$ goodness of fit tests (Heckman, 1984, Heckman and Walker. 1990) to the estimated and 
actual probabilities. In Table 5 we report the $p$-value of a joint test of the relative share of agents within each state conditional on all possible realizations of selected covariates. ${ }^{17}$

Table 5: Conditional Model Fit

\begin{tabular}{lllllllll}
\hline \multirow{2}{*}{ State } & \multicolumn{2}{c}{ Number of Children } & \multicolumn{2}{c}{ Baby in Household } & \multicolumn{2}{c}{ Parental Education } & \multicolumn{2}{c}{ Broken Home } \\
& SMM & ML & SMM & ML & SMM & ML & SMM & ML \\
\hline High School Dropout & 0.90 & 0.75 & 0.83 & 0.95 & 0.26 & 0.56 & 0.65 & 0.62 \\
High School Finishing & 0.99 & 0.99 & 0.99 & 0.99 & 0.96 & 0.99 & 0.97 & 0.89 \\
High School Graduation & 0.84 & 0.72 & 0.99 & 0.99 & 0.86 & 0.99 & 0.40 & 0.50 \\
High School Graduation (cont'd) & 0.67 & 0.90 & 0.98 & 0.98 & 0.90 & 0.98 & 0.37 & 0.42 \\
Early College Enrollment & 0.04 & 0.49 & 0.98 & 0.97 & 0.87 & 0.94 & 0.39 & 0.58 \\
Early College Graduation & 0.63 & 0.91 & 0.81 & 0.86 & 0.07 & 0.06 & 0.89 & 0.58 \\
Early College Dropout & 0.42 & 0.72 & 0.99 & 0.99 & 0.86 & 0.99 & 0.40 & 0.50 \\
Late College Enrollment & 0.27 & 0.62 & 0.99 & 0.94 & 0.14 & 0.25 & 0.84 & 0.96 \\
Late College Graduation & 0.56 & 0.11 & 0.97 & 0.99 & 0.07 & 0.06 & 0.72 & 0.97 \\
Late College Dropout & 0.71 & 0.77 & 0.62 & 0.17 & 0.08 & 0.89 & 0.45 & 0.89 \\
\hline
\end{tabular}

Overall, the level of $p$-values is high. For ML estimation, all $p$-values indicate that our model is consistent with the data at the 5\% significance level. In the case of SMM, we only do not pass the test conditional on Number of Children among early college enrollees. Because tests within covariates across all states are not independent, we use a Bonferroni test to evaluate the joint hypothesis that the predicted covariate distributions fit at each state. The test is based on the maximum $\chi^{2}$ statistic over all states for each covariate. We pass a 5\% Bonferroni test for all covariates and both estimation approaches.

Economic Implications Table 6 presents the median ex ante gross returns $G R^{a}\left(\hat{s}^{\prime}, \tilde{s}^{\prime}, s\right)$ and net returns $N R^{a}\left(\hat{s}^{\prime}, \tilde{s}^{\prime}, s\right)$ of pursuing a higher education by transitioning from $s$ to $\hat{s}^{\prime}$. Both capture all current and future earnings. However, they differ with regards to current and future costs. Their systematic parts are included in the calculation of the $N R^{a}\left(\hat{s}^{\prime}, \tilde{s}^{\prime}, s\right)$ but not the $G R^{a}\left(\hat{s}^{\prime}, \tilde{s}^{\prime}, s\right)$ as we discussed in

${ }^{17}$ In the $\chi^{2}$ test, the predicted conditional distributions depends on estimated parameters. We do not adjust the test statistic to account for parameter estimation error as suggested by Heckman (1984) because the adjustments are usually slight (Heckman and Walker, 1990). 
Section 2.2.

Table 6: Economic Implications

\begin{tabular}{lcccccc}
\hline & \multicolumn{3}{c}{ Gross Return } & \multicolumn{3}{c}{ Net Return } \\
State & True & ML & SMM & True & ML & SMM \\
\hline High School Finishing & $28 \%$ & $35 \%$ & $33 \%$ & $66 \%$ & $62 \%$ & $138 \%$ \\
Early College Enrollment & $14 \%$ & $18 \%$ & $18 \%$ & $-2 \%$ & $-1 \%$ & $-4 \%$ \\
Early College Graduation & $71 \%$ & $75 \%$ & $61 \%$ & $48 \%$ & $48 \%$ & $93 \%$ \\
Late College Enrollment & $28 \%$ & $30 \%$ & $29 \%$ & $-23 \%$ & $-21 \%$ & $-58 \%$ \\
Late College Graduation & $22 \%$ & $22 \%$ & $16 \%$ & $9 \%$ & $6 \%$ & $24 \%$ \\
\hline & \multicolumn{3}{c}{ ML } & & \multicolumn{3}{c}{ SMM } \\
\hline RMSE & \multicolumn{3}{c}{0.03416} & & 0.29775 \\
\hline
\end{tabular}

Notes: Statistics calculated for ML and SMM approaches based on 50,000 simulated agents using the parameter estimates. RMSE = root-mean-square error calculated in units of $100 \%$.

The estimates for the gross returns $G R^{a}\left(\hat{s}^{\prime}, \tilde{s}^{\prime}, s\right)$ are very similar for the two approaches and close to their true values. However, for the net returns $N R^{a}\left(\hat{s}^{\prime}, \tilde{s}^{\prime}, s\right)$ only the ML results are close to the truth. The SMM results are off by up to a factor of two. For example, the true net return of finishing high school is $66 \%$, while SMM estimates $138 \%$. The RMSE is roughly one order of magnitude larger for SMM than ML estimation. This difference is solely driven by the discrepancies in the net returns.

Table 7 sheds light on the poor performance of our SMM approach in the estimation of the net returns. These, in contrast to the gross returns, include the current costs and the systematic part of all future costs of educational choices. SMM is unable to detect the systematic differences in the cost faced by agents. We overestimate the variance of the unobserved component determining choices $\sigma_{\eta_{\left(s^{\prime}, s\right)}}$. Too much of the agents' decisions is attributed to random cost shocks and not their systematic differences. This translates into an excess net return as we underestimate the cost associated with future educational choices. Despite encouraging values for model fit criteria, SMM fails to accurately estimate the net return to educational choices. 
Table 7: Standard Deviations

\begin{tabular}{lccc}
\hline & \multicolumn{3}{c}{$\hat{\sigma}_{\eta_{\left(s^{\prime}, s\right)}}$} \\
State & True & ML & SMM \\
\hline High School Finishing & 0.27 & 0.24 & 0.61 \\
Early College Enrollment & 0.20 & 0.19 & 0.47 \\
Early College Graduation & 0.61 & 0.60 & 1.30 \\
Late College Enrollment & 0.22 & 0.20 & 0.56 \\
Late College Graduation & 0.61 & 0.60 & 1.30 \\
\hline RMSE & & 0.016 & 0.496 \\
\hline
\end{tabular}

Notes: RMSE = root-mean-square error.

We also explore the impact of a 50\% reduction in tuition cost on agents' college going decisions. We simulate 50,000 agents from our model and compare their educational choices under the baseline regime and the policy alternative using the results from the two estimation approaches. Based on the ML results, all policy predictions line up with the underlying truth. This is only partly true for the SMM estimation, where the predicted graduation rate for those induced to enroll in college late is too optimistic. Only a quarter will actually graduate, while the SMM results forecast about half. The SMM's failure to distinguish between the systematic and unsystematic cost components driving educational choices translates into (partly) flawed policy conclusions as well.

We now investigate the poor performance of our application of SMM and start with some evidence that we indeed recover a global minimum of our criterion function. Figure 6 shows the value of $\Lambda(\psi)$ around our SMM estimates as we perturb all parameters in a random direction in $t$ increments. All perturbations increase the discrepancies between the observed and simulated sample. However, $\Lambda(\hat{\psi})$ is not zero because of remaining differences between estimated and true structural parameters. Even if we set $\hat{\psi}=\psi^{*}$, then $\Lambda\left(\psi^{*}\right)$ evaluates at 434 (horizontal dashed line) due to the random variation in agents' behaviors and state experiences. The moments provide noisy information about the data generating process due to the random components. The more variation due to unobservables, the less 
information is contained in the data. As it turns out, the value of the criterion function evaluated at our estimates $\hat{\psi}$ is actually slightly smaller than $\Lambda\left(\psi^{*}\right)$.

Next we consider alternative choices for: (1) set of moments $\hat{f}(\psi),(2)$ number of replications $R,(3)$ weighting matrix $W$, and (4) optimization algorithm.

Figure 6: Criterion Function

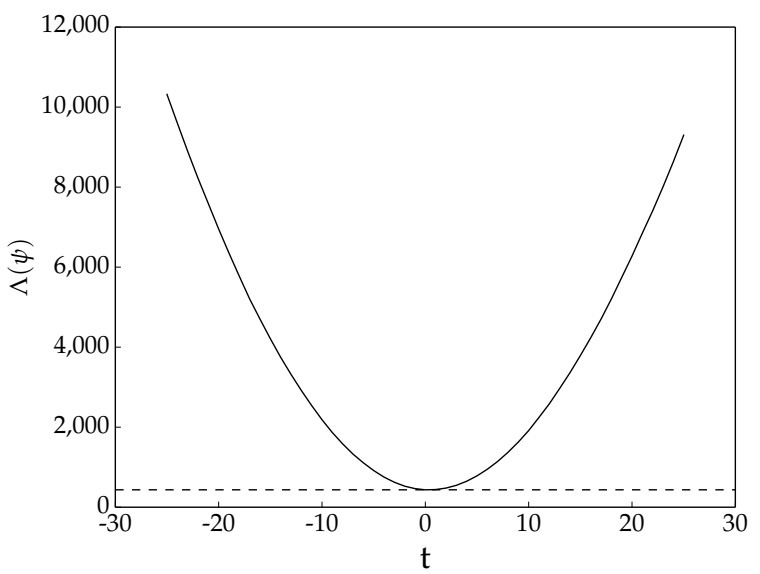

Notes: Investigation using estimation sample of 5,000 agents with 30 replications.

Set of Moments We use the sequential schooling model of Heckman et al. (2014b) to inform our choice of moment conditions in the spirit of EMM estimation (Gallant and Tauchen, 1996). For our baseline, we match a number of conditional moments such as parameters of OLS regressions for within state earnings and LP models characterizing the state transitions. We explicitly include determinants of future costs and earnings among the regressors in the LP models to capture the dynamics of agents' educational choices. We add aggregate statistics of the data such as average earnings and their standard deviations as well as state frequencies. In Table 8, we study alternative sets of moment conditions. In particular, we specify a cross-sectional version in which we do not include future outcome covariates in the models of educational choice. We also study three alternative sets of dynamic moments. We increase their number from 440 up to 868, adding moments that provide additional information about the observed agent transitions. We thereby hope to improve the estimation of the systematic differences in the psychic cost of educational choices. We add a dynamic Probit model for each transition (Alt. A) and correlations of state outcomes and each covariate $(Y(s), X(s))$, between outcomes over time $\left(Y(s), Y\left(s^{\prime}\right)\right)$, and correlations of choice indicators with current cost covariates 
$\left(G\left(s^{\prime}\right), Q\left(\hat{s}^{\prime}, s\right)\right)$ (Alt. B).

Table 8: Set of Moments

\begin{tabular}{|c|c|c|c|c|}
\hline \multirow[b]{2}{*}{ Sets } & \multirow{2}{*}{$\begin{array}{c}\text { Cross Section Moments } \\
\text { Base }\end{array}$} & \multicolumn{3}{|c|}{ Dynamic (Panel) Moments } \\
\hline & & Base & Alt. A & Alt. B \\
\hline \multicolumn{5}{|c|}{ Outcome Models } \\
\hline Means & $\checkmark$ & $\checkmark$ & $\checkmark$ & $\checkmark$ \\
\hline Standard Deviations & $\checkmark$ & $\checkmark$ & $\checkmark$ & $\checkmark$ \\
\hline Ordinary Least Squares & $\checkmark$ & $\checkmark$ & $\checkmark$ & $\checkmark$ \\
\hline Correlations & & & & $\checkmark$ \\
\hline \multicolumn{5}{|c|}{ Choice Models } \\
\hline State Frequencies & $\checkmark$ & $\checkmark$ & $\checkmark$ & $\checkmark$ \\
\hline \multicolumn{5}{|l|}{ Linear Probability } \\
\hline - cross section & $\checkmark$ & & & \\
\hline - dynamic & & $\checkmark$ & $\checkmark$ & $\checkmark$ \\
\hline \multicolumn{5}{|l|}{ Probit } \\
\hline - dynamic & & & $\checkmark$ & $\checkmark$ \\
\hline Correlations & & & & $\checkmark$ \\
\hline \multicolumn{5}{|c|}{ Overall Statistics } \\
\hline Number of Moments & 222 & 440 & 690 & 868 \\
\hline Number of Replications & 50 & 50 & 50 & 50 \\
\hline Weighting Matrix & \multicolumn{4}{|c|}{ diagonal variance matrix } \\
\hline Algorithm & \multicolumn{4}{|c|}{ POUNDerS } \\
\hline \multicolumn{5}{|c|}{ Quality of Fit Measures } \\
\hline$\Lambda(\hat{\psi})$ & 130.69 & 383.49 & 666.57 & 798.33 \\
\hline$\Lambda\left(\psi^{*}\right)$ & 222.12 & 434.07 & 685.94 & 847.64 \\
\hline
\end{tabular}

Notes: Alt. $=$ Alternative 
We also report the value of the criterion function at the true structural parameters $\Lambda\left(\psi^{*}\right)$. Its difference from zero is solely driven by the presence of the random disturbances $u_{r}$. The final values of our criterion function are always below $\Lambda\left(\psi^{*}\right)$ which gives us further confidence that we attained a global minimum in those cases.

We show the implications of alternative moments for the estimated median ex ante gross and net returns to education in Table 9 .

Table 9: Robustness of Economic Implications of Alternative Implementations of SMM

\begin{tabular}{lccccc}
\hline & & Cross Section Moments & \multicolumn{2}{c}{ Dynamic (Panel) Moments } \\
State & True & Base & Base & Alt. A & Alt. B \\
\hline \hline & & Gross Return & & & \\
\hline High School Finishing & $28 \%$ & $38 \%$ & $33 \%$ & $34 \%$ & $35 \%$ \\
Early College Enrollment & $14 \%$ & $18 \%$ & $18 \%$ & $19 \%$ & $19 \%$ \\
Early College Graduation & $71 \%$ & $74 \%$ & $61 \%$ & $67 \%$ & $61 \%$ \\
Late College Enrollment & $28 \%$ & $17 \%$ & $29 \%$ & $25 \%$ & $26 \%$ \\
Late College Graduation & $22 \%$ & $18 \%$ & $16 \%$ & $19 \%$ & $14 \%$ \\
\hline & & Net Return & & & \\
\hline High School Finishing & $66 \%$ & $154 \%$ & $138 \%$ & $137 \%$ & $137 \%$ \\
Early College Enrollment & $-2 \%$ & $-4 \%$ & $-4 \%$ & $-4 \%$ & $-4 \%$ \\
Early College Graduation & $48 \%$ & $89 \%$ & $93 \%$ & $94 \%$ & $93 \%$ \\
Late College Enrollment & $-23 \%$ & $-72 \%$ & $-58 \%$ & $-55 \%$ & $-56 \%$ \\
Late College Graduation & $9 \%$ & $16 \%$ & $24 \%$ & $22 \%$ & $24 \%$ \\
\hline
\end{tabular}

Notes: Statistics calculated for SMM based on 50,000 simulated agents using the parameter estimates.

Once dynamic moments are included in the criterion function, the effect of adding even more is rather small. The estimates for the gross and net returns are all very similar. However, when using 
only cross-sectional moments for the criterion function, the performance of SMM deteriorates and its ability to recover the net returns is undermined further.

We assess the information content of selected moments $\hat{f}_{i}$ and investigate the effect of perturbations around $\hat{\psi}$. In Figure 7 , we perturb the intercept in the structural earnings equation for early college graduates in $t$ increments. This has a direct effect on average earnings in that state (Figure 7a). However, agents are forward-looking and these changes also affect moments associated with earlier decisions such as finishing high school (Figure 7b). This is true even though the immediate benefits of doing so (Figure 7c) are unaffected. Agents change their early educational choices due to the increase in the option value of finishing high school, which includes the expected future value of potentially graduating from college.

Figure 7: Parameter Perturbations, Outcome

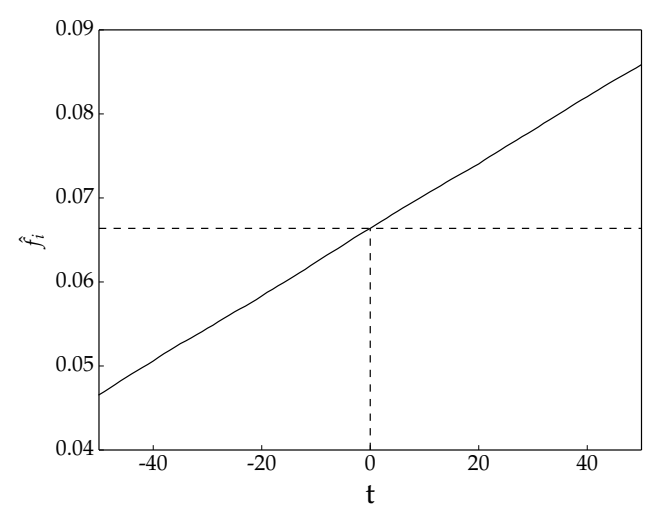

(a) College Graduation, Average Earnings

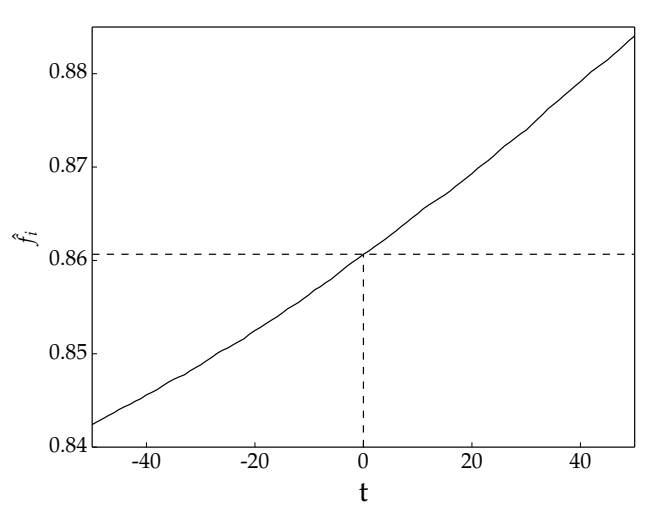

(b) High School Finishing, State Frequency

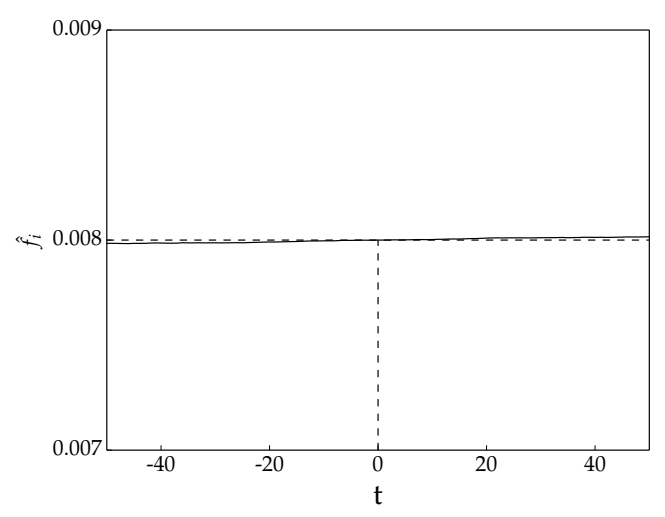

(c) High School Finishing, Average Earnings 
Number of Replications For a given set of structural parameters, we create multiple simulated datasets from which we calculate the moments. Averaging over those moments, we reduce the effect of random components determining agents' choices and state experiences. In Figure 8 we show the value of the criterion function at the true structural parameters $\psi^{*}$ for different numbers of replications $R$. The difference from zero is solely driven by the random components determining agents' choices and outcomes. If the model is simulated only once, then $\Lambda\left(\psi^{*}\right)$ takes value 825. Initially, increases in $R$ result in a large drop of $\Lambda\left(\psi^{*}\right)$. However, this effect levels off after more than 20 replications. Afterwards, the value of $\Lambda\left(\psi^{*}\right)$ oscillates around 435. In a finite sample, differences between $\check{f}$ and $\hat{f}\left(\psi^{*}\right)$ remain even for a very large number of replications. While the random values of $\left(\epsilon(s), \eta\left(\hat{s}^{\prime}, s\right)\right)$ wash out in the simulated moments, their particular realizations remain relevant in the finite observed data ${ }^{18}$ For our baseline estimates we set $R=30$. Further increases do not change model fit or economic implications.

Figure 8: Role of Replications

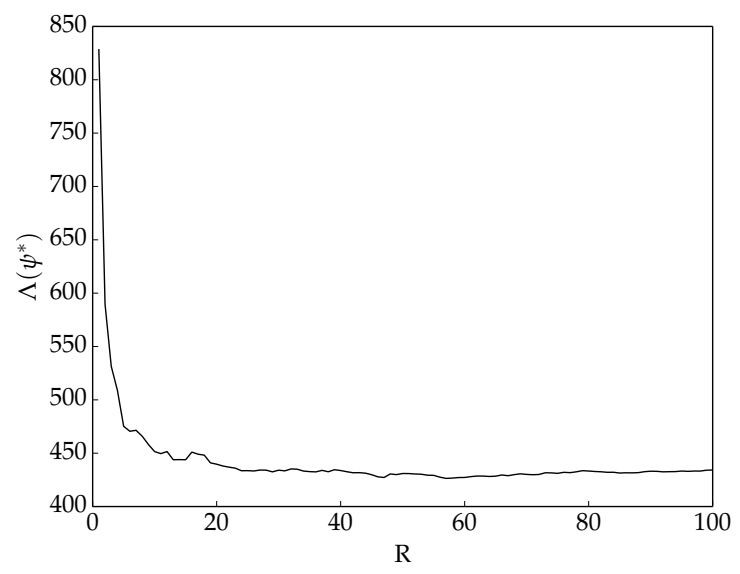

Notes: Investigation using estimation sample of 5,000 agents with varying number of replications.

Weighting Matrix Our optimization algorithm is only guaranteed to converge to local minimizers. Figure 9 plots the surface of our criterion function around $\psi^{*}$ for two alternative choices of $W$ given the true values of $u_{r}$. Thus, $\check{f}=\hat{f}\left(\psi^{*}\right)$ and $\Lambda\left(\psi^{*}\right)$ evaluates initially to zero regardless of the weighting

${ }^{18}$ See Kristensen and Salanié (2011) for a comprehensive statistical analysis of estimation methods, where the objective function is approximated through simulation or discretization. 
matrix used. Then we perturb all the structural parameters in a random direction in $t$ increments. We show the surface of $\Lambda(\psi)$ when either the identity matrix (Figure 9a) or the diagonal matrix with the variances of the moments (Figure $9 \mathrm{~b}$ ) is used. Choosing the identity matrix for $W$ results in multiple local minima, whereas using the variances smoothes the overall surface of the criterion function.

Figure 9: Alternative Weighting Matrices

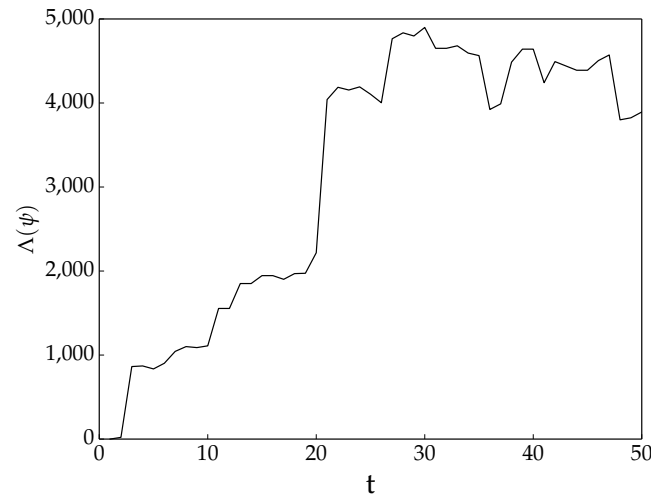

(a) Identity Matrix

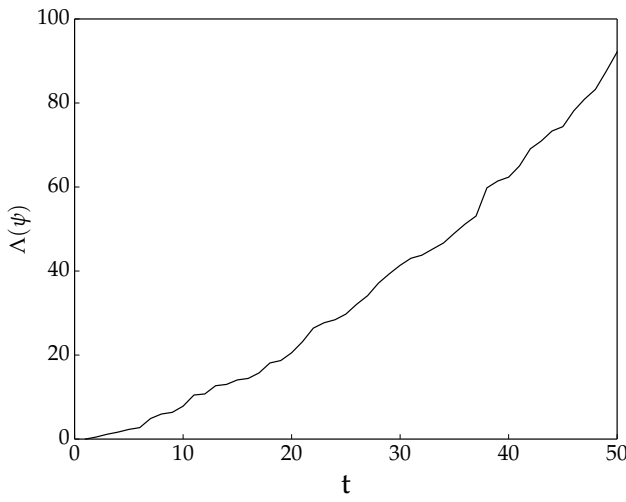

(b) Inverse Variances on Diagonal

Notes: Investigation using estimation sample of 5,000 agents with one replication and alternative weighting matrices.

Optimization Algorithm Because we repeat the SMM estimation many times for our Monte Carlo study, we benefit from a fast optimization algorithm. In Figure 10 we compare the performance of POUNDerS to the standard Nelder-Mead algorithm (Nelder and Mead, 1965) applied by Del Boca et al. (2014) and French and Jones (2011) among others. We perturb our estimates $\hat{\psi}$ and run the two algorithms as implemented in the Toolkit for Advanced Optimization (TAO) (Munson et al., 2012) to investigate their relative performance. Following Moré and Wild (2009) the solvers are tested using their default options ${ }^{19}$ Both algorithms are derivative-free, but differ in their search strategy and how they exploit the structure of the criterion function. Nelder-Mead applies a direct search method, while

${ }^{19}$ We are aware that performance can change for other choices. However, our practical experience throughout this project lines up with the results from this stylized presentation. We illustrate the relative performance of the two algorithms using a single processor only. Both algorithms allow parallel implementations as well (Lee and Wiswall, 2007; Munson et al., 2012). 
POUNDerS forms an approximation model within a trust region which exploits the special structure of our nonlinear least-squares problem. We show a minute-by minute account of the criterion function $\Lambda(\psi)$ over five hours.

Figure 10: Optimization Algorithms

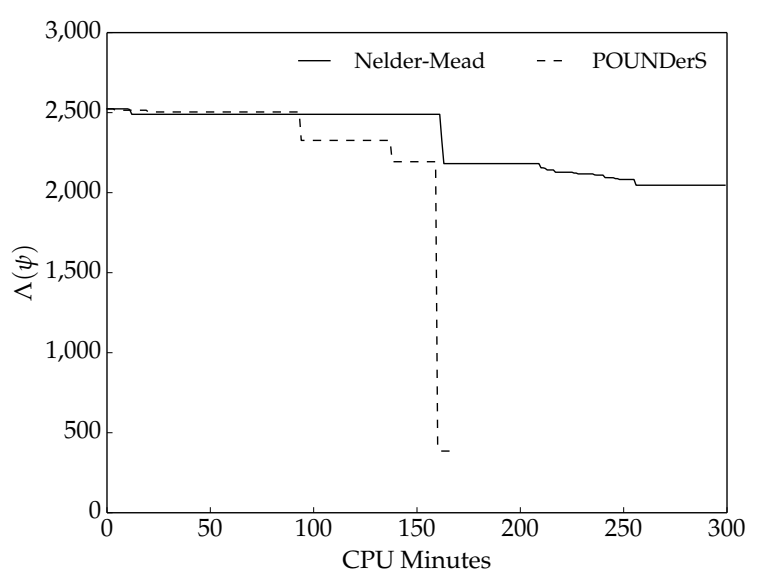

Notes: Investigation using estimation sample of 5,000 agents with 30 replications and all tuning parameters of the algorithms set to their default values.

The POUNDerS algorithm attains a lower bound of $\Lambda(\psi) \approx 385$ after about two and a half hours and terminates. With the Nelder-Mead algorithm, the criterion function still takes a value of $\Lambda(\psi) \approx 2,050$ after five hours. Even after 36 hours, the Nelder-Mead solution $\Lambda(\psi) \approx 1,126$ is still about three times as large as the POUNDerS solution.

We are unable to improve the SMM results by using alternative tuning parameters. Our discussion cautions that inspection of model fit statistics alone does not guarantee accurate economic implications. For our model, large unobserved variation in educational choices translates into a noisy criterion function, which leaves SMM unable to recover the true returns to education. The structural variances of the unobserved cost shocks are poorly estimated; we are unable to correctly distinguish between the systematic and unsystematic cost components of educational choices.

Our results do not discredit SMM as a useful tool for the estimation of complex economic models. Our results are highly model dependent, but our diagnostics are not. We now outline a Monte Carlo exercise that allows SMM users to build confidence in their particular implementation in any applied 
setting.

Monte Carlo Exercise to Gain Confidence in an SMM Algorithm. Let $\mathcal{M}(\psi)$ denote the structural model parametrized by $\psi$ which is fit to the observed data $D^{o b s}$ to produce an estimated set of parameters $\hat{\psi}^{o b s}$ using SMM.

Step 1 Simulate a synthetic sample $D^{s y n}$ from $\mathcal{M}\left(\hat{\psi}^{o b s}\right)$ using the estimated results.

Step 2 Fit $\mathcal{M}(\psi)$ on the synthetic sample $D^{s y n}$ using SMM to produce $\hat{\psi}^{\text {syn }}$.

Step 3 Compare $\hat{\psi}^{o b s}$ to the results from the synthetic sample $\hat{\psi}^{\text {syn }}$.

Using the initial estimates as the parametrization for the Monte Carlo exercise ensures that important features of the data generating process, in our case the large unobserved variability in agent behaviors, are accounted for. In Step 2, it is crucial to follow the same estimation approach applied to the original data as closely as possible, e.g. choice of starting values. Combining the application of fast state of the art optimization algorithms with parallel computing allows for such an analysis even in computationintensive models.

This exercise showcases the performance of the estimator in a favorable setting as the model is correctly specified. If the structural parameters $\hat{\psi}^{s y n}$ are successfully recovered, this is encouraging but does not provide a definite proof of the performance in the observed data. A failure, however, offers reason for concern. The algorithm might be improved, for example, by varying the set of moments used to test SMM.

\section{Conclusion}

We compare the performance of simulated method of moments (SMM) and maximum likelihood (ML) estimation in dynamic discrete choice models. We estimate a simplified dynamic model of educational choices which emphasizes the role of unobserved heterogeneity, psychic costs, and option values for the net returns to schooling. The primary value of the model comes as input to the simulation study that is the core of this paper. 
We estimate our model on a sample of white males from the National Longitudinal Survey of Youth of 1979 (NLSY79). We discuss its implications for schooling decisions and present estimates of option values by cognitive and non-cognitive factors. Given our estimates, we simulate a synthetic sample, creating a realistic setting to compare ML and SMM estimation. Our model allows for ML estimation without the need for any simulation in the likelihood function, which provides a clean comparison of ML against simulation-based estimation methods such as SMM. ML and SMM pass standard model fit tests. However, while the ML estimates are close to the true structural objects of interest, our version of SMM fails to recover the true net returns to education and policy effects. The SMM is unable to distinguish between systematic and unsystematic cost components driving educational choices.

We investigate alternative tuning parameters for implementing our SMM procedure. We specify alternative sets of moment conditions and show how the benefit of additional moments depends on the unique information they provide. Moments that capture the dynamics of agent behavior are crucial for getting reliable estimates of dynamic models. A large replication count in the simulation step reduces the effect of random noise in the measurement of the criterion function. An appropriate choice of the weighting matrix smoothes the surface of the criterion function and reduces the risk of local minima. Based on our analysis, we recommend that more exacting model specification tests and Monte Carlo evidence be provided to verify the performance of SMM in any application. 


\section{References}

Aвbott, B., G. Gallipoli, C. Meghir and G. L. Violante, “Education Policy and Intergenerational Transfers in Equilibrium," Working Paper 18782, National Bureau of Economic Research, February 2013.

AdDa, J., C. Dustmann, C. MeghiR And J.-M. Robin, “Career Progression, Economic Downturns, and Skills," Working Paper 18832, National Bureau of Economic Research, February 2013.

Adda, J., C. Dustmann And K. Stevens, “The Career Costs of Children," Working Paper 6201, Institute for the Study of Labor, December 2011.

ANDERSEN, T. G., L. BENZONI AND J. LUND, “An Empirical Investigation of Continuous-Time Equity Return Models," Journal of Finance 57 (December 2002), 1239-1284.

Andersen, T. G., H.-J. Chung AND B. E. SOREnSEN, “Efficient Method of Moments Estimation of a Stochastic Volatility Model: A Monte Carlo Study," Journal of Econometrics 91 (July 1999), 61-87.

Arcidiacono, P. And R. A. Miller, “Conditional Choice Probability Estimation of Dynamic Discrete Choice Models with Unobserved Heterogeneity," Econometrica 79 (November 2011), 1823-1867.

BARTLETt, M. S., “The Statistical Conception of Mental Factors," British Journal of Psychology 1 (July 1937), 97-104.

Bureau OF LABOr STATISTICS, NLS Hanbook 2001: The National Longitudinal Surveys (Washington, DC: U.S. Department of Labor, 2001).

CAmeron, S. V. AND J. J. HeCKMAN, “The Nonequivalence of High School Equivalents," Journal of Labor Economics 11 (January 1993), 1-47.

Carneiro, P., K. HANSEn And J. J. Heckman, “Estimating Distributions of Treatment Effects with an Application to the Returns to Schooling and Measurement of the Effects of Uncertainty on College Choice," International Economic Review 44 (April 2003), 361-422.

CARrasco, M. AND J.-P. Florens, "Simulation-Based Method of Moments and Efficiency," Journal of Business E Economics and Statistics 20 (October 2002), 482-492. 
Comay, Y., A. Melnik And M. A. PollatscheK, "The Option Value of Education and the Optimal Path for Investment in Human Capital," International Economic Review 14 (June 1973), 421-435.

CUnHA, F., J. J. HeCKMAN AND S. NAVARRO, “Separating Uncertainty from Heterogeneity in Life Cycle Earnings," Oxford Economic Papers 57 (April 2005), 191-261.

— "The Identification and Economic Content of Ordered Choice Models with Stochastic Thresholds," International Economic Review 48 (November 2007), 1273-1309.

Cunha, F., J. J. HeCKMAN And S. SCHENNACH, "Estimating the Technology of Cognitive and Noncognitive Skill Formation," Econometrica 78 (May 2010), 883-931.

Del BocA, D., C. Flinn And M. Wiswall, "Household Choices and Child Development," Review of Economic Studies (January 2014), 137-185.

ECKSTEIN, Z. AND K. I. WOLPIN, “The Specification and Estimation of Dynamic Stochastic Discrete Choice Models: A Survey," The Journal of Human Resources 24 (Autumn 1989), 562-598.

— "Why Youths Drop Out of High School: The Impact of Preferences, Opportunities, and Abilities," Econometrica 67 (November 1999), 1295-1339.

FLINN, C. AND D. DEL BOCA, “Endogenous Household Interaction," Journal of Econometrics 166 (January 2012), 49-65.

FlinN, C. AND J. MABLI, “On-the-Job Search, Minimum Wages, and Labor Market Outcomes in an Equilibrium Bargaining Framework," Working Paper 91, Carlo Alberto Notebooks, December 2008.

FRENCH, E. AND J. B. JONES, "The Effects of Health Insurance and Self-Insurance on Retirement Behavior," Econometrica 79 (May 2011), 693-732.

GACH, F. AND B. M. PÖTSCHER, "Nonparametric Maximum Likelihood Density Estimation and Simulation-Based Minimum Distance Estimators," Mathematical Methods of Statistics 20 (December 2011), 288-326.

Gallant, A. R. And G. Tauchen, "Which Moments to Match?," Econometric Theory 12 (October 1996), 657-681. 
GEWEKE, J. F., “Bayesian Inference in Econometric Models using Monte-Carlo Integration,” Econometrica 57 (November 1989), 1317-1339.

Gouriéroux, C. AND A. Monfort, Simulation-Based Econometric Methods (New York, NY: Oxford University Press, 1997).

Gouriéroux, C., A. Monfort And E. M. Renault, "Indirect Inference," Journal of Applied Econometrics 8 (December 1993), S85-S118.

Hajivassiliou, V. AND D. L. McFAdDEN, "The Method of Simulated Scores for the Estimation of LDV Models," Econometrica 66 (July 1998), 863-896.

Hansen, K., J. J. Heckman And K. Mullen, “The Effect of Schooling and Ability on Achievement Test Scores," Journal of Econometrics 121 (July 2004), 39-89.

Heckman, J. J., "Heterogeneity and State Dependence," in S. Rosen, ed., Studies in Labor Markets (Chicago, IL: University of Chicago Press, 1981), 91-140.

- "The $\chi^{2}$ Goodness of Fit Statistic for Models with Parameters Estimated from Microdata," Econometrica (November 1984), 1543-1547.

Heckman, J. J., J. E. Humphries And T. Kautz, eds., The Myth of Achievement Tests: The GED and the Role of Character in American Life (Chicago, IL: University of Chicago Press, 2014a).

Heckman, J. J., J. E. Humphries And G. Veramendi, “Education, Health and Wages," mimeo, The University of Chicago, March 2014b.

Heckman, J. J., L. J. LOCHNER AND P. E. TODD, “Earnings Functions, Rates of Return and Treatment Effects: The Mincer Equation and Beyond," in E. A. Hanushek and F. Welch, eds., Handbook of the Economics of Educationvolume 1 (Amsterdam, Netherlands: Elsevier, 2006a), 307-458.

Heckman, J. J. AND S. NAVARro, “Dynamic Discrete Choice and Dynamic Treatment Effects," Journal of Econometrics 136 (February 2007), 341-396.

Heckman, J. J., R. Pinto And P. A. Savelyev, “Understanding the Mechanisms Through Which an Influential Early Childhood Program Boosted Adult Outcomes," American Economic Review 103 (October 2013), 2052-2086. 
Heckman, J. J., J. StiXRUd AND S. URzÚA, “The Effects of Cognitive and Noncognitive Abilities on Labor Market Outcomes and Social Behavior," Journal of Labor Economics 24 (July 2006b), 411-482.

Heckman, J. J. AND J. R. WALKER, “The Relationship Between Wages and Income and the Timing and Spacing of Births: Evidence from Swedish Longitudinal Data," Econometrica 58 (November 1990), 1411-1441.

Hotz, V. J. ANd R. A. Miller, "Conditional Choice Probabilities and the Estimation of Dynamic Models," The Review of Economic Studies 60 (July 1993), 497-529.

Johnson, M. T., “Borrowing Constraints, College Enrollment, and Delayed Entry," Journal of Labor Economics 31 (October 2013), 669-725.

JudD, K. L. AND B. SKRAINKA, “High Performance Quadrature Rules: How Numerical Integration Affects a Popular Model of Product Differentiation," CeMMAP Working Papers, November 2011.

KeAne, M. AND A. A. SMIth, “Generalized Indirect Inference for Discrete Choice Models," mimeo, Yale University, November 2003.

KEANE, M., P. E. TODD AND K. I. WOLPIN, “The Structural Estimation of Behavioral Models: Discrete Choice Dynamic Programming Methods and Applications," in O. Ashenfelter and D. Card, eds., Handbook of Labor Economicsvolume 4A (Amsterdam, Netherlands: Elsevier, 2011), 331-461.

KeAne, M. And K. I. Wolpin, “The Solution and Estimation of Discrete Choice Dynamic Programming Models by Simulation: Monte Carlo Evidence," Review of Economics and Statistics 76 (November 1994), 648-672.

KeAne, M. P., “A Computationally Practical Simulation Estimator for Panel Data," Econometrica 62 (January 1994), 95-116.

KeAne, M. P. AND K. I. WOlPIN, “The Career Decisions of Young Men," Journal of Political Economy 105 (June 1997), 473-522.

— , "The Effects of Parental Transfers and Borrowing Constraints on Education," International Economic Review 42 (November 2001), 1051-1103. 
Kortelainen, M., T. Lesinski, J. Moré, W. Nazarewicz, J. Sarich, N. Schunck, M. V. Stoitsov AND S. Wild, "Nuclear Energy Density Optimization," Physical Review C 82 (August 2010), 024313.

KRINSKY, I. AND L. A. RobB, “On Approximating the Statistical Properties of Elasticities,” The Review of Economics and Statistics 68 (November 1986), 715-719.

— , "On Approximating the Statistical Properties of Elasticities: A Correction," The Review of Economics and Statistics 72 (Febrary 1990), 189-190.

Kristensen, D. And B. SAlaniÉ, "Higher-order Properties of Approximate Estimators," mimeo, Columbia University, June 2011.

LeE, D. AND M. Wiswall, "A Parallel Implementation of the Simplex Function Minimization Routine," Computational Economics 30 (September 2007), 171-187.

LEE, D. AND K. I. WOLPIN, "Intersectoral Labor Mobility and the Growth of the Service Sector," Econometrica 74 (January 2006), 1-46.

—, "Accounting for Wage and Employment Changes in the U.S. from 1968-2000: A Dynamic Model of Labor Market Equilibrium," Journal of Econometrics 156 (May 2010), 68-85.

McFadden, D. L., "A Method of Simulated Moments for Estimation of Discrete Response Models without Numerical Integration," Econometrica 57 (September 1989), 995-1026.

MoRÉ, J. J. AND S. M. WILD, “Benchmarking Derivative-Free Optimization Algorithms,” SIAM J. Optimization 20 (March 2009), 172-191.

Munson, T., J. SARich, S. Wild, S. Benson And L. C. MCInnes, “TAO 2.0 Users Manual,” Mathematics and Computer Science Division, Argonne National Laboratory (July 2012).

Nelder, J. A. AND R. Mead, “A Simplex Method for Function Minimization,” The Computer Journal 4 (January 1965), 308-313.

Nickl, R. AND B. M. PÖtSCher, “Efficient Simulation-Based Minimum Distance Estimation and Indirect Inference," Mathematical Methods of Statistics 19 (December 2010), 327-364. 
Nocedal, J. AND S. J. WRIGHT, Numerical Optimization (New York, NY: Springer, 2006).

Press, W. H., B. P. Flannery, S. A. TeukOlsky AND W. T. VetTerling, Numerical Recpies in Fortran 77: The Art of Scientific Computing (New York, NY: Cambridge University Press, 1992).

RAKNERUD, A. AND O. SKARE, "Indirect Inference Methods for Stochastic Volatility Models Based on Non-Gaussian Ornstein-Uhlenbeck Processes," Computational Statistics and Data Analysis 56 (November 2012), 3260-3275.

Ruge-MurciA, F., “Estimating Nonlinear DSGE Models by the Simulated Method of Moments: With an Application to Business Cycles," Journal of Economic Dynamics and Control 36 (June 2012), 914-938.

SKRAINKA, B. S., "A Large Scale Study of the Small Sample Performance of Random Coefficient Models of Demand," mimeo, The University of Chicago, October 2011.

Trachter, N., "Stepping Stone and Option Value in a Model of Postsecondary Education," Working Paper 14-03, Federal Reserve Bank of Richmond, February 2014.

WeIsBroD, B. A., "Education and Investment in Human Capital," Journal of Political Economy 70 (October 1962), 106-123.

WOLPIN, K. I., The Limits of Inference Without Theory (Cambridge, MA: MIT Press, 2013). 